\title{
STUDIES OF CEREBRAL FUNCTION IN LEARNING
}

\author{
K. S. LASHLEY
}

The Department of Psychology of the University of Minnesota

CONTENTS

1. The problem of nervous function in learning $\ldots \ldots \ldots \ldots, \ldots \ldots \ldots, 55$

General questions.................................. 55

Program of experiments................................ 65

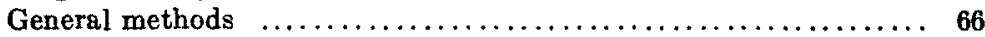

II. The relation of cerebral injury to the general activity of the rat.... 68

III. The effects of cerebral in jury upon learning ability . . . . . . . . . 73

Problems and methods...............................

Experimental data................................. 76

Summary of data................................... 90

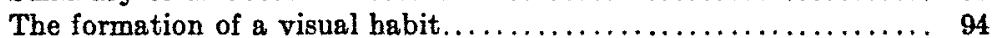

The effects of destruction of deep-lying structures $\ldots \ldots \ldots \ldots \ldots .97$

IV. The relation of the rate of learning to the amount of cerebral injury.. 98

Bearing of the experiments on cerebral function in learning ....... 101

V. The function of the cerebrum in the retention of a habit of visual discrimination ..................................... 103

Apparatus and methods............................... 104

Records of experiments.............................. 106

Summary of data.................................. 111

VI. The stimulable cortex and the corpus striatum in relation to disturbances of motor coördination and to learning ................ 115

The electro-stimulable cortex of the rat. .. . . . . . . . . . . . . 116

The character of lesions in paretic animals................ 117

The function of the motor area in learning. . . . . . . . . . . . 122

VII. The significance of the general results for the cerebral mechanism of learning $\ldots \ldots \ldots \ldots \ldots \ldots \ldots \ldots \ldots \ldots \ldots \ldots \ldots \ldots \ldots \ldots \ldots \ldots, 123$

General summary $\ldots \ldots \ldots \ldots \ldots \ldots \ldots \ldots \ldots \ldots \ldots \ldots \ldots, 126$

\section{THE PROBLEM OF NERVOUS FUNCTION IN LEARNING}

\section{General questions}

We are, most of us, accustomed to think of learning in terms of nerve cells, synapses, changes in conduction of nerve impulses, etc., but it must be borne in mind that some recent writers deny 
the necessity for any specialized structures and, indeed, consider all learning, even of the conditioned reflex type, to be an inherent function of protoplasm. This view has been advanced chiefly by Neo-Lamarckians beginning with Hering and Butler and extending to Semon, Driesch, Rignano, and F. Darwin among recent writers. The great mass of evidence upon which their contentions are based is without firm foundation, consisting as it does of inferences drawn from evolutionary series, and the few experimental facts which are adduced, such as the results of Schroeder and Kammerer, lack verification. Even if established they would not bear directly upon the relation of somatic induction to learning. Nevertheless, the contention for the possibility of extra-neural learning can not be dismissed summarily upon the basis of established facts. The most recent contribution toward a theory of extra-neural learning is that of Kappers (17) in which it is assumed that excitatory processes are conducted through non-nervous tissue, directing growth processes and nervous integration. The doctrine (neurobiotaxis) seems to have been received favorably by many neurologists. It is, however, based wholly upon deductions from anatomical data. Nowhere in the studies of growth or evolution has a case of learning been actually observed.

Have we any evidence that learning in the individual is possible in the absence of differentiated conduction paths? A few years ago one might have been tempted to say that a demonstration of learning in protista would give a positive answer to this question. But the recent publications of Sharp ('14), Yocom ('18), Taylor ('19) and others suggest that protista have well differentiated conduction systems. Even in Amoeba, in which there is no indication of structural differentiations of this character, the observations of Kepner and Taliaferro ('13) show that reactions may occur at a point far distant from the point of stimulation, as when stimulation between two pseudopods results in change in direction of movement at their tips. So, while some observations, particularly those of Metalnikow ('12), indicate that the protozoa are capable of forming habits, we must conclude that there is no known case of learning in 
an organism which is not equipped with a differentiated conduction system.

The theories of the mnemonic nature of growth and evolution and of extra-neural learning in general need therefore not detain us further here. There is certainly need for continued investigations in these fields, but whatever the condition in embryonic tissues may be, it is evident that learning in the individual is chronologically and functionally first and that in all metazoa, at least, learning is coexistent with differentiated conductive tissue.

Whether or not learning is restricted solely to the activity of this tissue is, however, not certainly established. It has been suggested by the writer ('17) and by Dunlap ('17) that endocrine activity may play a part in the fixation of habit but some recent experiments (to be reported in another paper) make this seem improbable. There is no conclusive evidence for the general activity of any extra-neural structure in learning while there is clear evidence that nervous organization is of fundamental importance for the process. Upon the mechanism of nervous activity in learning we have no direct observations but studies of the mechanism of nervous conduction in general define rather clearly the type of activity which we may expect to find.

The most important neurological concept bearing upon nervous function in learning is that of the reflex character of all behavior. Theories of the fixation of "traces" in particular cells or areas of the brain and of the arousal of images by the excitation of these cells or areas have now little more than historical interest. The doctrine of the image seems pretty well exploded and the vast amount of data upon the reflex nature of spinal and bulbar reactions accumulated within recent years leaves little room for doubt that every reaction of the organism is carried out by transmission of impulses over reflex paths differing only in the number of cells and the complexity of organization intervening between receptor and effector. The problem of nervous function in memory is, then, no longer one of the locus in which memories are stored; we can not hypothetize with Ferrier ('76) 
ideas of movement stored in the motor area and ideas of sensation in the sensory areas, or with Loeb ('00) resonant vibrations involving the whole of the brain. The trained organism differs from the untrained in its reflex reactions and it is the task of physiology to trace through the reflex paths which determine these reactions and to describe the mechanism by which the direction of conduction is altered.

The problem here seems clear enough but methods of solving it are far to seek. We can not trace nerve impulses directly; we can not make chemical analysis of individual nerve cells and even if this were possible we could not interpret the results until we had some notion of what cells are functional in learning. An attempt at correlation of the learning function with structural differentiations of the nervous system seems to offer almost the only present means of attacking the problem. Is the capacity for formation of new functional connections inherent in all nervous tissue, or is it characteristic only of a certain type of organization? Does reintegration occur in the simple nerve net or only after the appearance of synaptic connections? In what portions of the reflex are and in what gross divisions of the nervous system does reintegration occur? Through what portions of the nervous system are the propagated impulses of learned reactions transmitted? Is there any type of nervous organization which is particularly favorable to learning? Answers to these and similar questions may help us to formulate experimental problems bearing more directly upon the mechanism of fixation of habits.

The questions which yield most easily to experimental attack are those dealing with the function of gross anatomical divisions of the nervous system. A good bit of evidence bearing upon them has already been accumulated but its inconclusive character may be judged from the conflicting opinions of recent investigators. One finds statements to the effect that learning occurs only as a function of the cerebrum (Loeb, '00; Lloyd Morgan, '12), that it may occur also in lower centers (Luciani, '15; Bechterew, '09), that it is the result of the combined,action of all parts of the cerebrum (Loeb, '00), that it is a function of 
a particular part of the cerebrum, (Sollier, '00; Franz, '07). Many of these and similar statements are based upon purely metaphysical grounds, as Morgan's doctrine of the cerebrum as the seat of consciousness. Others are based upon an inadequate experimental analysis of the problem, and much more experimental data must be accumulated before we can subscribe fully to any of the theories of nervous function in learning.

Before we outline the problems of nervous localization in learning and methods for attacking them it is necessary to recognize clearly that learning and retention may result from the activity of distinct nervous mechanisms. It is conceivable that the conditioned-reflex paths which mediate the learned reaction are established in one portion of the nervous system, under the directive influence of some other part of the nervous system which functions only during the learning process and is unnecessary for the production of the learned reaction. The hypotheses which imply that learning requires the conscious direction of the cerebrum although learned reactions may be carried out altogether at subcortical levels imply such a condition. On the other hand the attempts made by Max Meyer ('11), Watson ('14), and others to account for learning in terms of reintegration of simple reflex arcs assume that no other nervous organization is necessary for learning than that included in the reflex arcs which are reintegrated and communicating cells between them. There is no certain evidence to support either one of these hypotheses and the question can be settled only by a detailed examination of the function of every part of the nervous system during learning and in the performance of learned reactions. Before this is carried out extreme care in distinguishing learning and retention in interpreting experimental data will be necessary.

The greater part of the existing experimental and theoretical work centers about the problem of the function of the cerebrum in learning. Since the present investigation deals with certain aspects of this problem a brief review of the experimental work which has been done upon cerebral function in learning may serve to connect the somewhat detached sections of the paper and bring them into relation to the fundamental problems. 
A. The question of prime importance for habit theory is that of the existence of anatomical divisions of the nervous system to which the function of learning is restricted. The discovery of such a region would give an opportunity for the study of the roble of finer structural differentiations, but there is no real evidence that any such specialization exists. The evidence advanced in support of the contention that the cerebrum of mammals is the sole seat of the learning process is this:

1. Invertebrates, lacking a cerebrum are incapable of associative memory (Loeb, '00). This argument was advanced before many tests of lower animals had been made. The demonstration of complex learning in all phyla above the coelenterates annuls it.

2. Total destruction of the cerebrum is followed by the loss of most of the learned reactions of the organism. The observations of Flourens, Schrader, Goltz, Rothmann, and many others establish this beyond a doubt. But in no case have the observations upon decerebrate animals been sufficiently detailed to prove that all habitual acts are abolished by the operation. The average habitual acts observed by investigators have been of a complex type requiring tremendously complex coordinations of reactions to kinesthetic and external stimuli and no data are available upon the persistence of simple conditioned reflexes. The experiments of Rothmann (cited below) show either the retention of some habits after complete decerebration or their reacquirement after the operation: in either case a strong argument against the limitation of learning to the cerebrum. Lashley and Franz ('17) found that simple habits were retained by the rat after destruction of very large portions of the cerebrum, embracing all except the temporal and basal portions. Finally the experiments reported in section $V$ of this paper show that a simple habit may be retained after the destruction of any given third of the cortex.

3. The formation of habits is not possible in the complete absence of the cerebrum. In practically every case this conclusion has been advanced without any serious attempt to train the animals, on the basis of the general impression of stupid- 
ity given by them. Without careful training experiments such observations are absolutely worthless. My own experience with an animal of the present series illustrates this. The rat (number 19, section III) had extensive destruction in the frontal and parietal regions. She had a paresis of the right legs which made her walk stumbling and uncertain, disturbance of the musculature of the face and excessive length of teeth which gave her an expression of extreme stupidity. She seemed to wander about aimlessly, rarely reacting to stimuli which influenced normal animals. Several people who saw her remarked her stupidity and predicted that she would never learn the problem and this was also my impression. Yet the animal learned the difficult double-platform box in 27 trials, which is less than one fifth of the average of normal animals, and showed in overtraining tests a constancy of performance rarely equalled by normals.

But few attempts have been made to train animals after complete destruction of the cerebrum. The observations of Goltz ('92) upon his decerebrate dog extended over a period of more than eighteen months and some efforts were made to train the animal (to back out of a narrow stall) but the author feared to continue training because of the danger of producing convulsions and death by continued stimulation. The result of the tests were negative, but Goltz admits that the training was not continued long enough to justify the conclusion that the animal could not learn. Aside from the rapid recovery of walking coördinations which was probably a concomitant of recovery from shock, he reports no improvement except that of finding food. The swallowing reflex could not be elicited at first except by placing food in the pharynx. Gradually the reflex came to be called out by more distal stimuli to the tongue, chewing movements appeared, and on the twenty-fourth day after the operation food was first taken when placed against the lips. A similar improvement was reported by Rothmann ('12) who did not give the time for recovery. Rothmann further reported that his dog learned to accommodate the stepping movements of his hind legs to follow the movements of a chair 
upon which his fore feet were supported. These alterations in behavior may have been merely a result of gradual recovery from shock but they may with equal justice be interpreted as cases of simple learning.

The one outstanding experiment upon decerebrate animals is that of Burnett ('12), who failed to obtain the formation of the maze-habit by decerebrate frogs. His experiments were well controlled and seem to demonstrate that the decerebrate frog is incapable of forming so complex a habit, but they do not rule out the possibility of learning of a simpler type. As Franz and the writer have pointed out, the disorganization which follows decerebration is so great that many of the factors which are ordinarily effective in inducing learning (for instance, the sexual impulses) are no longer present and unless the training methods are adjusted very carefully to the condition of the animal negative results of training can have little significance.

The experimental work does seem to show that destruction of the cerebrum abolishes the vast majority of learned reactions and that decerebrate animals have a greatly reduced capacity for learning, but it does not show conclusively that it completely eliminates all ability to learn. This insistance upon the possibility of learning in the absence of the cerebrum may seem needless quibbling when there is so little evidence that noncerebral learning plays any important part in the behavior of higher animals, but the point is one of the greatest importance for learning theory since upon it hinges the question of whether learning is the product of some particular kind of nervous organization or is a capacity of all integrated nervous tissue; whether the cerebrum is a highly specialized organ or is merely a mass of reflex paths comparable in all save complexity to the spinal cord.

( The evidence from comparative anatomy suggests that the cerebrum is not essential for reintegration of reflex ares and data upon the vicarious function of various parts of the cerebrum, upon retention of habits after destruction of any given part of the cerebrum, and upon learning in partially decerebrate animals all tend to substantiate this view. A final judgment of the matter must await further evidence. 
B. In the absence of certain evidence for the restriction of the function of learning to special structures we may ask whether there is any sort of nervous organization which is particularly well adapted for learning, any structures whose functional activity facilitates learning. The question is more complicated than at first appears and should perhaps be stated in a different way. Given equally strong incentives for learning and problems equally well adapted to the innate equipment of the organism, will learning take place any more rapidly because of the presence of any special type of nervous organization? The mere demonstration that animals with a complex cerebrum are capable of learning complex problems more rapidly than those at a lower evolutionary level will not answer the question. A bird will learn to fly more quickly than a man and a man to speak more rapidly than a bird, but these facts do not prove that simple conditioned reflexes are formed any more rapidly in one than in the other when the conditions of the experiment are adapted to the two organisms. The rate of acquirement of complex habits is dependent upon many factors besides the actual rate of fixation of new integrations. The preexisting habits of the organism, the number and variety of instinctive responses available, the complexity of organization of existing reaction systems, perhaps the mere number of unemployed association fibers in the nervous system, all may influence the rate of learning, even though the underlying mechanism is the same. The phylogenetic evidence is not sufficient to prove that there has been any specialization of structure to facilitate learning.

Such experimental work as bears on the question indicates a lack of any important specialization for learning. Destruction of the frontal lobes is followed by loss of habits, yet animals lacking the frontal lobes may learn as rapidly as normal ones (Franz, '02, '07). The slow improvement in human reëducation after cerebral injury might be interpreted as proving the reverse, but reëducation demands the establishment of an enormous number of habits and the rate of improvement in the aphasic, for example, can not be compared with that of a normal adult, but only with that of the child first learning to speak. Measured 
by this standard, the progress of reeducation is not surprisingly slow. Results indicating slower learning after cerebral lesion are significant for this question only when the rate of learning is independent of preexisting habits. Experimental work where this condition has been met covers only the frontal region of the cerebrum and must be extended to other parts as well.

C. A number of observations establish the fact that learned reactions are mediated by certain regions of the cerebrum, the frontal and parietal association areas in higher mammals, the frontal pole in the rat. Is the function of these areas truly associational, that is, do they function in the reintegration of habits as such, or do they take part in the performance of the habit simply because they lie, anatomically, between the necessary afferent and efferent projection areas? In other words, do the association areas have a directive function in learning or are they masses of conductive tissue through which nerve impulses penetrate at random from afferent to efferent projection areas in the formation of new functional connections? There is no evidence which answers this question. Franz ('07) found that destruction of the frontal region of the brain of cat and monkey abolished recently formed habits, but the habits studied all had a kinaesthetic-motor foundation and it is not clear that all habits would be abolished by this operation provided that they had a different sensory basis. The problem can be attacked effectively only by the study of the acquirement of a variety of habits after the destruction of each and all of the association areas.

D. The suggestion of complete vicarious functioning of the parts of the cerebrum in learning, raised by Lashley and Franz and extended in this paper, raises the further question of the relation of the absolute quantity of cerebral material to the rate of learning. There seems to be no evidence bearing upon this point.

E. It has been suggested by many writers that habits which are practiced until they become automatic are thereby reduced to subcortical levels. The only experimental evidence bearing upon the point that I have been able to find is the statement 
by Franz that habits of long standing persisted after operations which abolished more recently acquired ones. His experiments do not seem to have precluded the possibility that the older habits involved reactions to different stimuli (auditory and visual) from those which called out the more recently formed ones (kinaesthetic). The opinion of other writers seems to be based chiefly on the desire to hustle unconscious reactions out of the cerebrum and there is no conclusive evidence that any habit which may be performed at subcortical levels was not acquired there in the first place.

These problems are perhaps the most fundamental ones icr an understanding of nervous function in learning which will serve as a foundation for investigation of the basic process of. reintegration. Many others of a somewhat more limited character are raised by the facts of cerebral localization in man but the facts in that field are too complex and too poorly understood to make a discussion of them in this limited space profitable. Still other problems are raised by the results of the present investigation and will be considered after the data have been presented.

\section{Program of experiments}

The experiments reported in the present paper bear upon many of the questions raised in the foregoing discussion but they were devised especially to test the following points:

1. Does cerebral injury give rise to disturbances in the general reactions of the rat such as would interfere seriously with learning, even though the essential structures for learning were still intact (section II)?

2. Is any part of the cerebrum especially efficient in learning irrespective of the type of sensory-motor coördination involved in the habit (section III)?

3 . Is there any relation between the mass of cerebral material functioning and the rate of learning (section IV)?

4. Is the frontal region, which is utilized in the formation of the inclined-plane box habit, functional in all learning, or is it utilized in this habit simply because of the particular sensorymotor coördinations involved (section V)?

PBYCROBTOLOG q, VOL. IX, NO. 1 
5. Does the motor area (determined by electrical stimulation and effects of destruction upon motor coördination) act as the final common path for learned reactions, or may the efferent impulses of learned reactions be transmitted from other regions (section VI)?

The methods employed were essentially those devised by Franz for the study of the frontal lobes; training the animals before or after operative destruction of cerebral areas and comparing their learning ability with that of normal animals.

\section{Operative technique}

The operations were performed under deep ether anesthesia. In every case a median longitudinal incision was made through the skin from the base of the skull to the anterior margin of the orbits, the hair having been removed by a depilatory. The skin was then drawn back to expose the entire dorsal surface of the skull. The operative field was mapped out in relation to the skull sutures and an opening of the required size was made with trephine and bone forceps. In case of bilateral operations the skull openings were made on both sides of the longitudinal suture to avoid injury to the longitudinal sinus.

The cerebral cortex was destroyed either by cauterization or by cutting it away from the underlying tissues with a cataract knife. For cauterization a small electric cautery was used, but owing to the quick cooling of its point and its inconvenient form it proved less satisfactory than the knife. In those experiments where it was used the fact is indicated. As soon as hemorrhage from the brain injury was checked the skin incision was closed by three stitches and covered with a cotton-celloidin dressing.

Since retention was tested shortly after the operation in some cases the question of irritation from the wound is of importance. In general the animals gave little evidence of discomfort after the operation. In three cases, after almost complete removal of one hemisphere, the animals ate heartily within thirty minutes after recovery from anesthesia. The positive results of the retention tests furnish the best evidence that irritation from the wound does not seriously interfere with the tests. 


\section{Determination of the extent of the lesions}

At the end of the experiments the animals were killed with ether and their brains removed, fixed in 15 per cent formalin, and imbedded in celloidin. Horizontal sections, $50 \mu$ in thickness, were cut and each fifth section was kept for study. The sections were drawn in outline under a projection microscope and the details of the lesions were filled in under higher pcwer, free hand. Owing probably to impurity of the alcohol used for dehydration the sections proved unusually resistant to stains and it was not always possible to make out cell details in them. For that reason, only areas in which the destruction of the cortex was obvious, as by complete absorption or by absolute separation from the remainder of the brain, were recorded as lesions. The lesions recorded represent therefore the minimal extent of injury; much larger areas than those indicated were almost certainly rendered nonfunctional by the section of their subcortical connections.

From the drawings of the sections the dimensions of the lesions were transferred with proportional dividers to correspond ing levels on the diagrams of the brain, the points so determinea were connected by lines, and the injured areas thus plotted were finally inked in. The method permits of some error, owing to disproportion between the sections and the diagrams, but it seems accurate enough for the present purpose. In addition to the diagrams of the dorsal and lateral aspects of each injured hemisphere a detailed camera drawing of one section was prepared. This was selected in the plane of the thalamus and lateral ventricles wherever possible. Because of limited space for reproduction these figures of sections had to be made somewhat diagrammatic. The degenerated cortex is indicated on them in solid black (plates 1, 2, and 3). 
II. THE RELATION OF CEREBRAL INJURY TO THE GENERAL ACTIVITY OF THE RAT

Various disturbances in the general activity of animals suffering from cerebral lesions have been described, such as restlessness in frontal cases or inertia and loss of emotional reactions after occipital injury. Although such changes have not been worked out carefully enough so that we may predict their occurrence after any given operation the possibility of their existence in operated animals complicates the study of the effects of cerebral lesions upon learning. Measures of learning ability of partially decerebrate animals based upon the rate of formation of a motor habit may be deceptive owing merely to differences in the general activity of the animals. The complicated problems which are adapted to the study of habit-formation in animals all demand the solution of some problem by overt trial and error and the fixation of certain parts of the reaction in habit. Theoretically, every animal must solve the problem at every trial so that differences in the amount of activity will make no difference in the amount of practice expressed in a given number of trials. But other factors besides frequency are instrumental in determining the rate of learning and among these the temporal element is of fundamental importance. The slow or inactive rat will require a longer time per trial than will the active one. Perhaps he will thus gain the advantage of distributed practice and thus learn with less effort; perhaps delays between the acts of the series to be associated will prolong the process of association as they do in the formation of the conditioned reflex. We have no means of determining, at present, what the real influence of such conditions will be. It becomes necessary, therefore," to control the general activity of the animals carefully, or where this is impossible, to determine the existence of individual variations in general activity so as to avoid the mistake of ascribing to specific cerebral injuries effects which are due merely to general ill health, or of interpreting slow learning as due to loss of problem-solving ability or to slowed rate of reintegration when its 
cause is in reality the loss of reinforcing or inhibiting mechanisms which determine only the tonic condition of the animal.

Before the results of training could be interpreted it was necessary, therefore, to make some estimate of the relative activity of normal and of partially decerebrate animals. Observations during training indicated that the normal animals were more given to excess activities, such as leaping over low obstacles (see page 92), than were the operated ones, but aside from this "friskiness" the normals seemed in no way more active than the operated animals. The latter spent little time in complete inactivity, moved quickly about the restraining cages, and reacted to stimuli as promptly as did normals. There was no indication of differences in general activity which might influence the rate of learning.

\section{Mclhods}

For a more accurate measure of the general activity of the groups whose rates of learning were compared, continuous records of activity for 240 hours were made for some of the animals trained and for other normal ones. These records were obtained by the use of a modification of the apparatus designed by Slonaker ('08). Four revolving cages were arranged so that their movements were recorded on a disk kymograph giving continuous records over twenty-four hour periods. A sample from such a record, covering six hours, is shown in figure 1 . The cages were pivoted so that the slightest movement of the animal within them would produce a break in the continuous line of the record sheet. The figure shows periods of continuous activity with rapid spinning of the cage (a), periods of practically complete quiescence $(b)$, and periods of slight activity, restlessness without active ruming $(c)$. Observations on the animals indicate that the periods of nearly complete inactivity are spent in sleep. Periods of partial activity are difficult to interpret and in dealing with the records statistically it seemed best to include only periods of active running and periods of complete quiet. The active ruming was computed as average 
hours per day during which the cage revolved almost continuously. Thus about 50 per cent of the hour at $d$ was spent in running and this was added to all other periods of great activity for the day. No period of inactivity was counted unless it was a full hour in length and the total inactivity is expressed as the average number of hours per day in which there was no activity. These rather arbitrary methods were selected because they set an absolute standard which may be recognized easily and is not subject to the errors which would arise if we attempted to estimate the total activity represented by such a curve as that at $c$. As an absolute measure of activity this method is

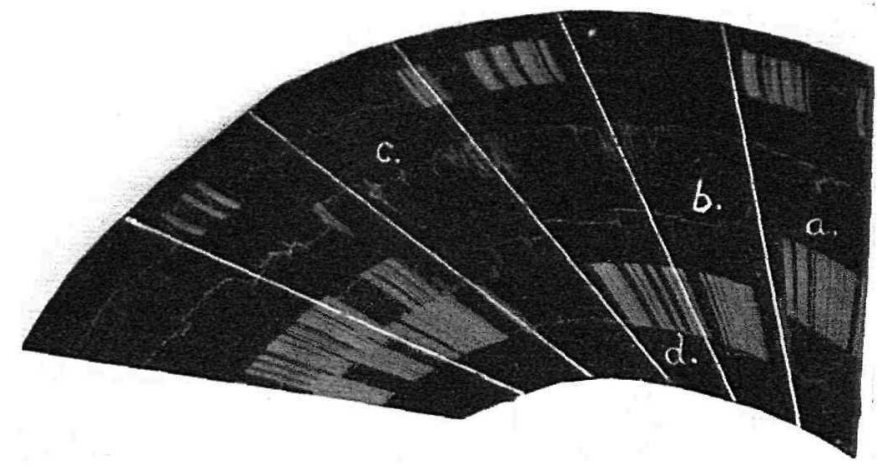

Fig. 1. A Record of the Actirity of Four Rats from 8 p.M. to 2 A.m.

$a$, Almost continuous running; $b$, complete rest; $c$, partial activity.

obviously inaccurate, but since the records of all the animals were treated in the same way the method of analysis is valid for comparative work.

\section{Results}

The determinations of general activity were made with normal animals and with individuals having each of the lesions dealt with in the training experiments. Their records for periods of great activity and for periods of inactivity are shown in table 1. As the records stand they indicate that the parietal cases were least given to active running, though not more than normally 
quiet, that the occipital and hemidecerebrate cases were slightly less active than normals, that the animals with frontal lesions were much more active than normals, and that those with frontal and parietal lesions were both more active and more restless than any of the others.

\section{TABLE :}

Duration of periods of great activity and of complete quiescence in normal animals and in animals after cerebral injury. The figures are based upon continuous records over $\$ 40$ hours for each animal. The total number of hours per day spent in active running is given in the first part of the table. The total number of hours per day in which there was little or no activity is given tn the second part. The numbers in parenthesis are those assigned to the animals in later experiments (section $I I I)$

\begin{tabular}{|c|c|c|c|c|c|c|}
\hline & \multicolumn{6}{|c|}{ POBTTION OF LEGSON } \\
\hline & Normal & $\begin{array}{l}\text { Hemide- } \\
\text { cerebrate }\end{array}$ & Occipital & Parietal & Frontal & $\begin{array}{l}\text { Fronto- } \\
\text { parietal }\end{array}$ \\
\hline Total activity .. & $\begin{array}{l}5.82 \\
2.55 \\
8.82 \\
4.31 \\
6.40\end{array}$ & $\begin{array}{l}2.67(1) \\
6.32(4) \\
5.19(5)\end{array}$ & $\begin{array}{l}0.92(7) \\
7.36(8) \\
4.85(9)\end{array}$ & $\begin{array}{l}3.73(11) \\
3.76(12) \\
3.50(13)\end{array}$ & \begin{tabular}{ll|}
5 & 34 \\
9 & 33 \\
8 & 90
\end{tabular} & $\begin{array}{l}7.02(18) \\
966(19)\end{array}$ \\
\hline Average $\quad . . \ldots$ & 5.58 & 4.72 & 435 & 3.66 & 7.86 & 8.34 \\
\hline Total rest .... & $\begin{array}{l}7.1 \\
4.9 \\
36 \\
8.6 \\
6.5\end{array}$ & $\begin{array}{r}10.3(1) \\
6.5(4) \\
5.8(5)\end{array}$ & $\begin{array}{l}3.4(7) \\
7.0(8) \\
9.5(9)\end{array}$ & $\begin{array}{r}55(11) \\
71(12) \\
12.6(13)\end{array}$ & $\begin{array}{l}9.9 \\
64 \\
4.3\end{array}$ & $\begin{array}{l}3.0(18) \\
26(19)\end{array}$ \\
\hline Average... & 6.14 & 7.50 & 6.63 & 8.4 & 6.8 & 2.8 \\
\hline $\begin{array}{l}\text { Average trials } \\
\text { for learning. }\end{array}$ & $\begin{array}{c}\text { quired } \\
\ldots \ldots\end{array}$ & 96.0 & 83.0 & 743 & & 39.0 \\
\hline
\end{tabular}

The apparently greater activity of the frontal cases might be explained by the fact that these animals were somewhat younger than the others rather than as due to the lesion but the assumption is not borne out by the behavior of the fronto-parietal cases which were much above the average in age. It seems rather that the heightened activity is the result of the cerebral injury, particularly as many other observers have reported 
increased restlessness after frontal injury in higher animals. The animals of each group are arranged in the same order in the two parts of the table so that their records for activity and rest may be compared. Usually a great amount of active running is accompanied by a reduced amount of time spent in absolute inactivity, but there are marked exceptions to this rule.

There is a great amount of individual variation between the members of each of the groups and there seems to be no constant relation between the amount of activity of the animals and the number of trials required by them for learning the problem on which they were trained. Three animals which showed little activity (numbers 1,7 , and 11 ) required many trials for learning $(141,107$, and 101 respectively), but one very inactive animal (13) learned in only 41 trials. Two very active animals (18 and 19) required few trials (51 and 27 respectively), but an equally active animal (8) required 97 trials for learning. There is no absolute correspondence between the general activity and the rate of learning.

The small number of animals studied and the great amount of individual variation makes the significance of differences between the groups very questionable. The test seems to have brought out the fact, however, that cerebral injury has no constant effect upon general activity which could account for any great differences in rate of learning found between normal and partially decerebrate animals.

A second question respecting the general activities of the operated animals is of great importance in interpretation of the results of training. Does destruction of parts of the cerebrum so disturb the instinctive behavior of the animals as to modify the effects of the stimuli used as incentives to learning? I have kept operated animals for periods up to five months after operation and have not been able to discover any change in their instinctive reactions. Animals of every group showed sexual activities, exploration of new situations, great eagerness for food after periods of starvation, efforts to be the bottom one of the pile when several animals slept together in one cage, etc. Except for motor inccördination which appeared in a few 
animals it would have been impossible to distinguish the operated animals from normals on the basis of any instinctive reaction, when once the immediate effects of the operation had worn off. (That the lack of motor coördination may lead to mistaken interpretation of other behavior has already been pointed out.) There is no evidence for any disturbance in instinctive reactions which might account for marked difference in learning ability.

III. THE EFFECT OF CEREBRAL INJURY UPON LEARNING ABILITY

\section{Problem and methods}

The first group of training experiments sought to measure the effect upon learning ability of the removal of various portions of the cerebral cortex, to determine whether or not any particular part of the cerebrum is necessary or is especially well adapted to the formation of complex habits. The method adopted was that of destroying a definite area of the cortex in each of a number of animals, varying the operations so as to cover all regions of the cortex in the total series of experiments; then to train the operated animals and compare their rates and methods of learning with those of normal animals.

Since there is a possibility that some simple habits are acquired wholly at subcortical levels (Franz and Lashley, '17) it seemed desirable to use a complicated problem for training. A second requirement of the problem to be learned was that it should demand some definite series of acts which could be recognized easily and which would be unlikely to appear as the result of pure chance, since the same problem was to be used for learning and for retention tests and time and error criteria alone are not very reliable tests of retention when applied to animals suffering from shock and motor disturbances following operation. A third requirement of the problem was that it should offer equal chances for learning to normal animals and to those which were weak as the result of operation. The inclined plane box with the plane situated above the door, used previously by Lashley and Franz, was not very satisfactory, since the operated animals sometimes had difficulty in climbing up to the plane. 
After some preliminary tests a combination-latch box was constructed which seemed to meet the above requirements. Its general plan is shown in figure 2. It consisted of the usual square, wire-covered box with a door $(d)$ which opened inward by the pressure of a spring. The door was held closed by latches attached to two metal platforms ( $a$ and $b$ ) at opposite ends of the box. The platforms were $10 \mathrm{~cm}$. long by $5 \mathrm{~cm}$. wide and

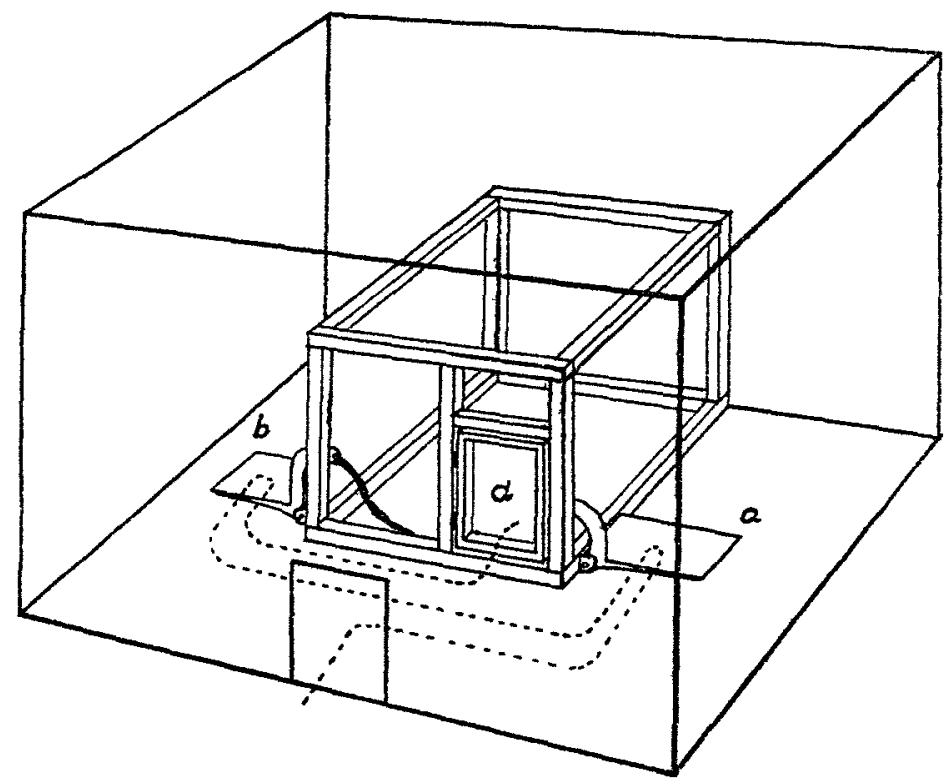

Fig. 2. The Dotble-Platform Box

$a$ and $b$, platforms which must be pushed down in the order $a-b$ in order to open the door, $d$, to the food box.

$2 \mathrm{~cm}$. above the floor. Their inner ends were hinged to the sides of the box and arranged to release the latches when their outer ends were depressed. By adjustable springs under the platforms the weight required to depress them could be regulated. Throughout the experiments they were adjusted so that a weight of 50 grams would just release the latches. The door was placed in the side of the box near one end. Pressure on the platform at that end (a) released one latch and allowed 
the door to move inward against the second latch. In this position of the door the first latch could not catch again. Pressure on the second platform $(b)$ would now release the second latch and allow the door to open.

As a result of this arrangement the door could be opened only by depressing the platforms in succession, beginning with the one nearest the door $(a)$. Pressure on the first platform $(a)$ caused only a faint click, pressure on the second platform (b) caused the door to open, but only after the first platform had been depressed.

Food was placed in the box and this was enclosed in a restraining cage which allowed a space of about $30 \mathrm{~cm}$. around the sides and top of the box. The animals were admitted through a small door in the restraining cage, opposite the door of the problem box. A stop-watch was started as soon as the animals entered the restraining cage. The times required to trip the first platform, to trip the second platform, and to enter the box were recorded. If the animal failed to open the box in an hour, except on the first trial, he was taken out and not fed. On the following day the latches were set as he had left them and the trial was continued. On the first trial inactive rats were allowed to remain in the restraining cage over night if necessary. Since none of the animals was fed in the problem box until after the first trial, the time of the first trial is significant only as a measure of general exploratory activity and it is not included in the comparison of times required for learning.

As it was not possible to breed rats in the laboratory in time for the work, the ancestry and exact age of the animals used in the experiments is unknown. All were young when purchased, however, and their age could be estimated roughly. All were between 120 and 180 days old at the time of operation, with the exception of numbers 1 and 17 which were older. Training was begun at intervals of from 13 to 43 days after the operation.

As a measure of learning the following arbitrary criterion was employed. The animal must go directly from the door of the restraining cage to plane $a$ and push down the platform; he must then go by some constant path to plane $b$ and after pushing it down must go directly to the open door and enter the problem 
box. Any deviation from the direct path or pause to sniff at the door or other part of the problem box was counted as an error. Three trials were given daily and three successive trials without error must be made in one day before learning was considered perfect.

\section{Experimental data}

Five types of operations were used for comparison and an attempt was made to test several animals with each type of lesion. The groups covered by the experiments were the following:

Group 1. Normal anımals 10

Group 2. One hemisphere I emoved

Group 3. Occipital regions of both hemispheres destroyed

Group 4 Parietal regions of both hemispheres destroyed 5

Group 5. Frontal polen of both hemispheres destroyed _. . 2*

Group 6. Frontal and parietal regions of both hemispheres destroyed

* The experiments of Lashley and Franz cover these regions and the training of these additional animals was undertaken only as a eheek on the earlier work.

The technique used in training all the groups was the same and there is no reason to believe that they differed in any other respect than the amount of functional cerebral cortex. The records of individual experiments follow.

Group 1. Normal animals. The ten normal animals were trained before the operative experiments were begun, as controls in an experiment on the action of drugs. Except for the season during which training was carried out, they did not differ from the operated animals, and the difference even here was slight, since training of the latter was begun before the normals had completely learned their problem. The records of the animals of this group are given in table 2. together with the records of the other groups, and their average time per trial in successive day's practice is shown in table 3.

The average number of trials required for learning by members of the group was $142.6 \pm 9.2$.

Group 2. Hemidecerelrate animals. In this group the object was to destroy one hemisphere completely while leaving the other intact. Complete destruction was obtained in only one case, 
TABLE 2

The average numbers of trials and range of variation in learning the double-platform box by normal and operated groups

\begin{tabular}{|c|c|c|c|}
\hline GrotP & LEsION & $\underset{\text { THLALS }}{\text { AVERAGE }}$ & $\begin{array}{l}\text { RANGR OP } \\
\text { VARIATION }\end{array}$ \\
\hline 1 & Normal. & 1426 & $63-204$ \\
\hline 2 & Hemidecerebrate $\ldots \ldots \ldots \ldots \ldots, \ldots$ & 87.2 & $49-141$ \\
\hline 3 & Occipital injury.. $\ldots \ldots \ldots \ldots \ldots, \ldots$ & 68.8 & $45-107$ \\
\hline 4 & Parietal injury $\ldots \ldots \ldots \ldots \ldots \ldots \ldots$ & 80.0 & 41-101 \\
\hline 5 & $\ldots \ldots \ldots \ldots \ldots$ & 900 & 90 \\
\hline \multirow[t]{2}{*}{6} & Fronto-parietal. $\ldots \ldots \ldots \ldots \ldots \ldots, \ldots$ & 39.0 & $27-51$ \\
\hline & All operated.... . . & 790 & $27-141$ \\
\hline
\end{tabular}

TABLE 3

The average time in seconds per trial, based on the average of each successive nine trials, required by the animals in each of the groups studied to go from the entrance of the restraining cage to the food

\begin{tabular}{|c|c|c|c|c|c|c|}
\hline \multirow{2}{*}{ NOMBER OF TRIAL } & \multicolumn{6}{|c|}{ GROUP NUMBER } \\
\hline & 1 & 2 & 3 & 4 & 5 & 6 \\
\hline $2-9$ & 429.5 & 173.9 & 330.2 & 1670.0 & 384.5 & 475.6 \\
\hline-18 & 132.2 & 81.2 & 61.5 & 95.4 & 116.2 & 87.5 \\
\hline-27 & 47.1 & 50.2 & 38.8 & 47.0 & 73.4 & 69.0 \\
\hline-36 & 40.5 & 33.8 & 39.3 & 26.6 & 29.8 & 12.6 \\
\hline-45 & 22.4 & 25.1 & 33.7 & 26.0 & 40.5 & 22.2 \\
\hline-54 & 13.7 & 22.2 & 298 & 25.9 & 569 & 10.5 \\
\hline-63 & 12.8 & 19.1 & 28.8 & 33.0 & 41.6 & \\
\hline-72 & 11.3 & 18.7 & 23.9 & 25.8 & 37.6 & \\
\hline-81 & 120 & 16.5 & 41.7 & 173 & 262 & \\
\hline-90 & 14.7 & 14.9 & 24.9 & 13.5 & 14.1 & \\
\hline-99 & 13.9 & 13.6 & 11.9 & 10.6 & 9.0 & \\
\hline-108 & 12.1 & 137 & 90 & 62 & & \\
\hline-117 & 10.6 & 143 & & & & \\
\hline-126 & 10.1 & 22.9 & & & & \\
\hline-135 & 10.4 & 14.0 & & & & \\
\hline-144 & 8.6 & 12.2 & & & & \\
\hline-153 & 9.4 & 11.0 & & & & \\
\hline-162 & 8.4 & & & & & \\
\hline-171 & 9.1 & & & & & \\
\hline-180 & 8.2 & & & & & \\
\hline-189 & 6.6 & & & & & \\
\hline-198 & 7.4 & & & & & \\
\hline
\end{tabular}


but in all of the others a very large proportion of the hemisphere was destroyed. Brief descriptions of the training and extent of the injuries in each of the animals follow.

Number 1. Large male. Left hemisphere injured by transverse and longitudinal incisions. Recovery was very rapid without discoverable sensory or motor disturbance. Training was begun 20 days after the operation. The reactions were prompt from the first and habitual reactions to the door of the problem box appeared on the fifth trial.

Number of trials required for learning .................. 141

Per cent of total cortex destroyed $\ldots \ldots \ldots \ldots \ldots \ldots \ldots \ldots \ldots \ldots, 27$

Lesion: Plate I, figure 1. The entire frontal pole of the left hemisphere cephalad to the corpus striatum was completely destroyed by a section extending into the olfactory tract. On the dorsal surface the lesion extended caudad to the posterior margin of the hippocampus, involving all the cortex overlying the corpus callosum. The cortex overlying the corpus striatum and the orbital surface remained intact. Behind this the lesion extended laterad to involve all the cortex overlying the hippocampus to the level of the posterior commissure. The underlying structures were practically uninjured.

Number 2. Large male. Left hemisphere injured by tranverse and longitudinal incisions, with an attempt to preserve the corpus striatum. Recovery was rapid without sensory or motor disturbance. Training was begun 20 days after the operation. The behavior of the animal seemed quite normal.

Number of trials required for learning $\ldots \ldots \ldots \ldots \ldots \ldots \ldots \ldots, 132$

Per cent of total cortex destroyed $\ldots \ldots \ldots \ldots \ldots \ldots \ldots \ldots \ldots, 40.7$

Lesion: Plate I, figure 2. The entire cortex of the left hemisphere, cephalad to the posterior margin of the lobus hippocampus had been separated from the underlying structures and was reduced to a thin membrane. A small area on the occipital pole and the cerebellar surface alone remained intact. The olfactory lobe was completely severed. The subcortical nuclei remained uninjured.

Number 3 . Small male. Left hemisphere injured by deep transverse and longitudinal incisions. He recovered somewhat slowly and showed a pronounced hemiparesis with ratation to the right in walking. The left vibrissae seemed insensitive and the behavior of the animal in 
walking with his left feet near the edge of a table suggested that of Vincent's blind rats after removal of the vibrissae. Training was begun 41 days after the operation. The animal was normally active, but at first failed to restrict his reactions to the problem box, as most normal animals do. Nevertheless, he learned with unusual quickness.

The brain was preserved 70 days after operation.

Number of trials required for leaning $\ldots \ldots \ldots \ldots \ldots \ldots \ldots \ldots \ldots, 54$

Per cent of total cortex destroyed $\ldots \ldots \ldots \ldots \ldots \ldots \ldots \ldots \ldots \ldots \ldots$

The brain was removed and fixed 91 days after operation.

Lesion: Plate I, figure 3. Practically all of the left hemisphere was destroyed, leaving only a thin membranous sac containing remnants of the corpus striatum and hippocampus surrounding the thatamus.

Number 4. Medium sized male. Right hemisphere injured by transverse and longitudinal incisions. He developed a slight paresis of the left legs with a possible reduction in the sensitivity of the left face. Training was begun 40 days after operation. The animal learned to go quickly to the platforms in the correct order, but usually merely sniffed at them and then ran to the door.

Number of trials required for learning $\ldots \ldots \ldots \ldots \ldots \ldots \ldots \ldots, 78$

Per cent of total cortex destroyed.

The brain was removed and fixed 90 days after the operation.

Lesion: Plate I, figure 4. The frontal pole of the right hemisphere was completely severed by a section passing just in front of the forceps of the corpus callosum. The dorsal surface of the hemisphere was destroyed except for a small area above the corpus striatum and another on the mesial surface of the occipital pole. On the lateral surface a section extended from the lateral ventricle through the posterior margin of the corpus striatum to the surface of the cortex, and the entire temporal and occipital regions caudad to this were degenerated and filled by a large cyst. The hippocampal lobe seemed to be uninjured, although compressed by the cyst. The posterior part of the corpus striatum was destroyed.

Number 5. Medium sized male. The left hemisphere was injured. He developed a marked right hemiparesis. Training was begun 40 days after the operation. His reactions to the problem box were normal.

Number of trials required for learning 72

Per cent of the total cortex destroyed 
The brain was removed and fixed 78 days after the operation.

Lesion: Plate I, figure 5. The lesion was practically identical in form with that of number 4 , but less extensive. The frontal pole was largely destroyed by a section passing from the lateral ventricle outward along the forceps of the callosum to the cortex. The cortex laterad to the corpus striatum was not degenerated, but its connections were almost certainly destroyed. This area is stippled in the diagram. The cortex laterad to the hippocampus was completely degenerated. The dorsal surface of the hemisphere was destroyed except for a narrow band along the mesial and occipital borders. The corpus striatum was intact but seemed to be separated from its posterior attachments.

Number 6. Small female, 68 days old at the time of operation. The left hemisphere was partly destroyed by a thermo-cautery. She developed a slight paresis which persisted for only a few weeks. Training was begun 30 days after the operation. After 8 days the animal became ill and training was suspended for 12 days. It was then resumed and completed.

Number of trials required for learning $\ldots \ldots \ldots \ldots \ldots \ldots \ldots \ldots 49$

Per cent of total cortex destroyed....................... 30.4

The brain was removed and fixed 60 days after operation.

Lesion: Plate I, figure 6. All the cortex on the dorsal surface from the forceps of the corpus callosum to the posterior margin of the hippocampus was destroyed. The lesion narrowed laterally to include only the area overlying the corpus striatum and fornix. The latter bodies were completely destroyed.

The results of these tests are summarized in table 2. The maximum number of trials required by any member of the group was 141 (1). The smallest number was 54 (3). The average number of trials is 82.7. The average time required per trial on successive day's training is shown in table 3 . The total extent of the lesions is shown in figure 3. Every portion of the left hemisphere and the greater part of the right was eliminated in one or another test, without significantly increasing the amount of practice required for learning. The maximum lesion appeared in number 3 (plate I, figure 3), including practically the entire left hemisphere. This animal learned more quickly than any of the others. 
Group 3. Occipital regions destroyed. In these tests the attempt was made to destroy the posterior third of the cortex of both hemispheres. Autopsies showed from 18 to 40 per cent of the cortex destroyed. Accounts of individual experiments follow.

Number \%. Large female, about 100 days old. The occipital lobes were destroyed by passing a scalpel through two trephine openings about $5 \mathrm{~mm}$. in front of the cerebro-cerebellar junction. Recovery was rapid without observable sensory or motor disturbance. Training was begun 27 days after the operation. The first three trials were made in very slow time, but thereafter reactions were prompt. Platform a was learned much more quickly than platform b; a marked exception to the usual rule.

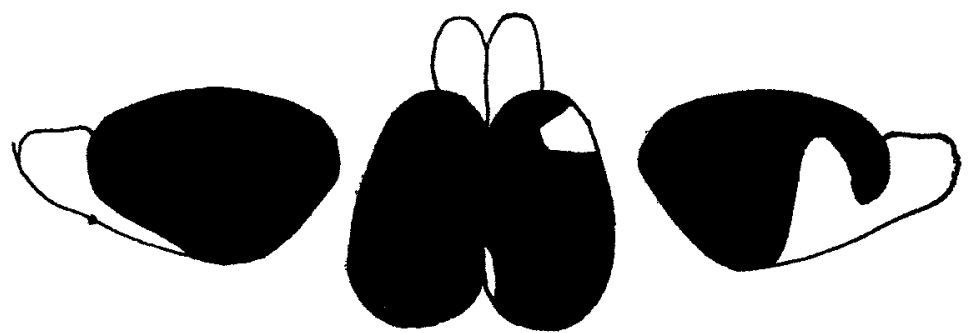

Fig. 3. The Total Extent of the Lesions in Animals of Grodp 2 After Operations on One Hemisphere

Number of trials required for learning $\ldots \ldots \ldots \ldots \ldots \ldots \ldots . \ldots 107$

Per cent of total cortex destroyed $\ldots \ldots \ldots \ldots \ldots \ldots \ldots \ldots \ldots, 32.1$

Lesion: Plate I, figure 7. Both occipital regions were completely destroyed above and caudad to the hippocampal lobes, except for a small area on the mesial surface of the left hemisphere at the level of the thalamus. The right hippocampal lobe was degenerated and the external capsules in the occipital lobes of both hemispheres were filled by large cysts.

Number 8. Large, vigorous male, about 120 days old. The occipital regions were destroyed with a thermo-cautery inserted through two trephine openings situated as in the foregoing case. Recovery was normal. Training was begun 18 days after operation. His reactions were prompt from the first: the position of the door was learned by the tenth trial. 
Number of trials required for learning. 97

Per cent of total cortex destroyed

Lesion: Plate I, figure 8. The lesions of both hemispheres were confined to the dorsal surface. The cerebellar surfaces of the cerebrum were intact. The hippocampal lobes were uninjured. The lesions extended laterad over the surfaces of the hippocampal lobes to the level of the fourth ventricle.

Number 9. Large male, about 200 days old. Both occipital lobes were injured with the cautery as above. Recovery was normal. Training was begun 22 days after the operation. The animal seemed quite normal in behavior, was aggressive and dominated the other males in the cage with him. In the problem box his reactions were prompt and the door was learned in six trails.

Number of trials required for learning $\ldots \ldots \ldots \ldots \ldots \ldots \ldots \ldots \ldots 45$

Per cent of total cortex destroyed.. ................... 40.8

Lesion: Plate I, figure 9. This animal showed the most extensive destruction of any of the occipital cases. The lesions of both hemispheres extended from the anterior edges of the hippocampal lobes caudad and laterad to include all of the cortex dorsad and laterad to the hippocampal lobes and all the posterior mesial surfaces except a small area on the left hemisphere at the level of the thalamus. The hippocampal lobes seemed intact.

Number 10. Small male, 102 days old. The occipital lobes were injured with a scalpel. Recovery was rapid with no noticeable disturbances of behavior. Training was begun 13 days after operation, before the animal had recovered his full strength. For the first two trials he was allowed to remain in the problem box over night. Thereafter his reactions were prompt.

Number of trials required for learning.. $\ldots \ldots \ldots \ldots \ldots \ldots \ldots, 82$

Per cent of total cortex destroyed

Lesion: Plate I, figure 10. On the right hemisphere the lesion extended over an area covering the dorsal and lateral surfaces of the hippocampal lobe, narrowing as it passed laterad and ending at the level of the fifth ventricle. The dorsal surface of the lobus hippocampus was destroyed. The lesion on the left hemisphere was similar but less extensive. 
The results of these tests are summarized in table 2 . The maximum number of trials required by any member of the group was 107 (7). The minimum number was 45 (9). The average number is 68.8 .

The total extent of the lesions is shown in figure 4. Every part of the occipital third of the cortex was destroyed in some one of the animals without any significant increase in the amount of practice required for learning. The average time per trial required in successive day's practice is shown in table 3 .

The greatest lesion appeared in number 9 (plate I, figure 9) and this animal learned more quickly than any of the others.

Group 4. Parietal region destroyed. In these experiments the attempt was made to destroy the middle third of the cortex, an

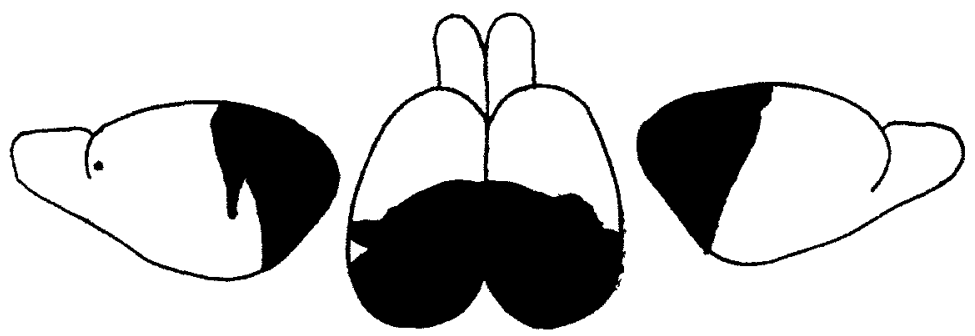

Fig. 4. The Total Extent of the Lesions in Animals of Grodp 3 After Operations on the Occipital Pole

area including the motor cortex of the hind legs and extending caudad to the visual cortex. Autopsy showed in each case a saddle shaped area, including from 14 to 31 per cent of the cortex, destroyed. Accounts of the individual experiments follow.

Number 11. Small female, about 150 days old. The parietal regions were injured by passing a scalpel laterad and messiad from each of two trephine openings just caudad to the fronto-parietal suture. Recovery was uneventful with no abnormalities of behavior. Training was begun 25 days after operation. The animal was inactive at first, but aften ten trials her reactions to the problem box became normal.

Number of trials required for learning ................... 101

Per cent of total cortex destroyed $\ldots \ldots \ldots \ldots \ldots \ldots \ldots \ldots \ldots, 21.2$ 
Lesion: Plate II, figure 11. The brain could not be sectioned owing to the presence of a large piece of bone which had become imbedded in the right hemisphere, extending into the lateral ventricle. The black area in the diagram indicates the extent of the large cyst occupying the parietal lobes of both hemispheres, as determined by gross dissection. The cortex in this area was completely absorbed, so that the thalamus and lateral ventricles were exposed. All of the cortex and that part of the corpus callosum overlying the lateral ventricals was destroyed.

Number 12. Small female, about 150 days old. Both parietal lobes were injured by an operation similar to that performed on number 11 . Recovery was normal without sensory or motor disturbance. Training was begun 27 days after operation and progressed normally.

Number of trials required for learning.. $\ldots \ldots \ldots \ldots \ldots \ldots \ldots, 81$

Per cent of total cortex destroyed $\ldots \ldots \ldots \ldots \ldots \ldots \ldots \ldots \ldots, 15.2$

Lesion: Plate II, figure 12. The lesion extends caudad from the region of the fronto-parietal suture to the anterior border of the hippocampus and laterad to the level of the floor of the lateral ventricles, involving the middle portion of the corpus callosum.

Number 13. Small male, about 100 days old. The parietal lobes were injured as in the case of number 11 . Recovery was rapid and training was begun 18 days after operation. The animal's reactions were prompt from the first and selective reactions to the platforms appeared on the fourth trial.

Number of trials required for learning $\ldots \ldots \ldots \ldots \ldots \ldots \ldots \ldots, 41$

Per cent of total cortex destroyed $\ldots \ldots \ldots \ldots \ldots \ldots \ldots \ldots \ldots \ldots, 31.5$

Lesion: Plate II, figure 13. On the right hemisphere the lesion extends from the knee of the corpus callosum caudad to the middle of the hippocampal lobe. Laterad it extends to the orbital surface and is continued as two narrow cuts which extend almost to the olfactory tracts and are united internally by a section through the external capsule which is outlined by small cysts. The lesion of the left hemisphere is similar in position but extends caudad only to the anterior margin of the hippocampus and laterad only to the plane of the upper limit of the lateral ventricle.

Number 14. Small male, about 100 days old. The parietal lobes were injured with a thermo-cautery. Recovery was rapid, but a slight right paresis persisted. Training was begun 25 days after operation. He reacted promptly to the problem-box situation but soon developed 
a stereotyped reaction to the second platform which delayed learning considerably.

Number of trisls required for learning.

99

Per cent of total cortex destroyed.

Lesion: Plate II, figure 14. On the dorsal surface of both hemispheres the lesion extended from the knee of the corpus callosum to the middle of the hippocampal lobes. On the right hemisphere it narrowed laterad, extending over the surface of the hippocampus. On the left hemisphere the lesion involved the same areas and in addition most of the cortex overlying the corpus striatum was destroyed. The lower nuclei seemed to be uninjured.

Number 15. Small female, 70 days old. The parietal areas were cauterized as in the case of number 14. Recovery was slow and the

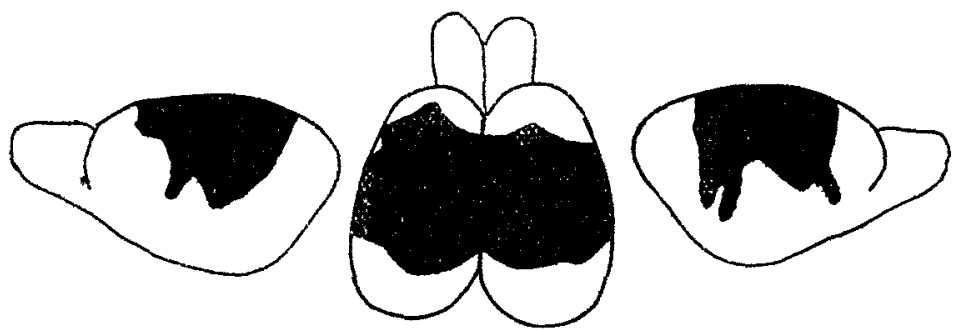

Fig. 5. The Total Extent of the Lesions in Animals of Grodp 4 After Operations in the Parietal Region

animal was still weak at the beginning of training. Reactions were prompt from the first and learning progressed normally.

Number of trials required for learning $\ldots \ldots \ldots \ldots \ldots \ldots \ldots \ldots .78$

Per cent of total cortex destroyed......................... 14.2

Lesion: Plate II, figure 15. The lesions on both hemispheres were confined to small areas lying above the lateral ventricals and corpora striata. Subcortical structures were uninjured.

The results of these tests are summarized in table 2 . The maximum number of trials required by any member of the group was 101 (11). The smallest number was 41 (13). The average number of trials is 80 . The average time required per trial on successive days' training is shown in table 3 . 
The total extent of the lesions is shown in figure 5. The entire middle third of the dorsal surface of the cerebrum was covered. The injuries on the lateral surfaces do not include all of the temporal lobes. No one of the animals of this group required as many trials for learning as the average of normals.

The greatest extent of injury appeared in number 13 (plate II, figure 13) and this animal learned more quickly than any of the others.

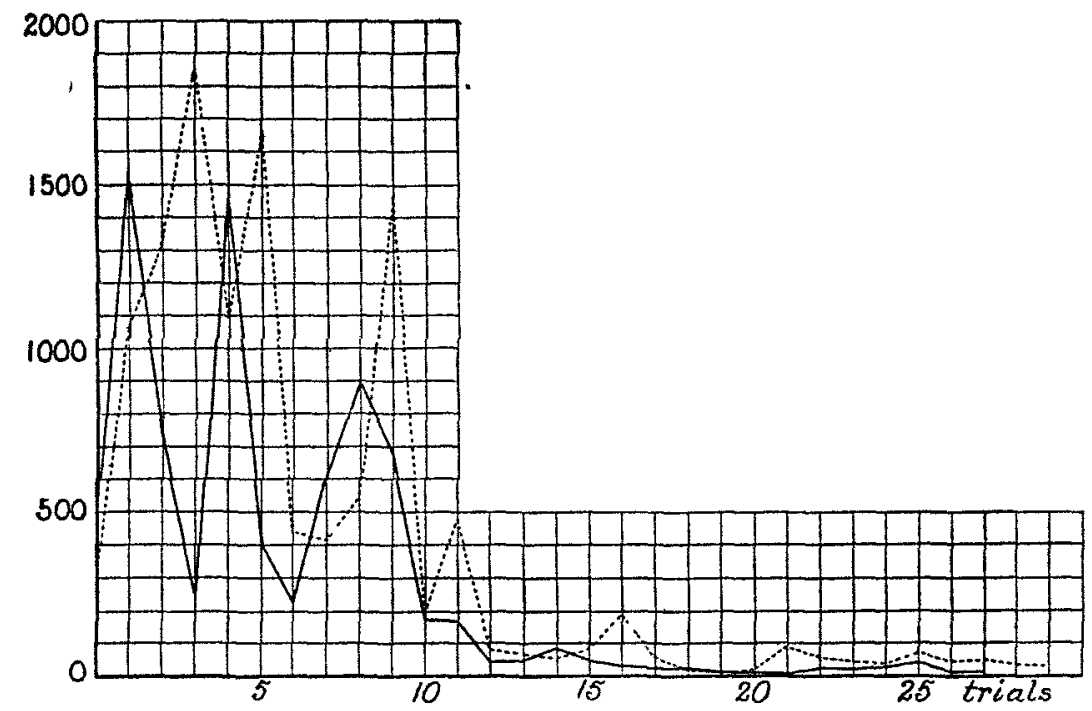

Fig. 6. A Comparison of the Rate of Learning in Normal animals and in Animals after Frontal Operations

The average time in seconds per trial is plotted. Normal rats: - - Operated rats - - From Lashley and Franz, '17.

Group 5. Frontal pole destroyed. In earlier work this area was covered rather thoroughly by experiments on the inclined-plane box. In that work six animals were trained on the inclined-plane box after injury to the frontal pole of the cortex and their average rate of learning was compared with that of normals on the same problem. The curves showing the rates of learning of these two groups are reproduced in figure 6 . The total extent of the lesion in the six animals is shown in figure 7. There was no significant difference between these groups (Lashley and Franz, '17). 
For comparison with this work two animals have been trained on the more complicated double-platform box after destruction of the frontal poles of the cerebrum. Brief descriptions of their records follow.

Number 16. Large female, about 200 days old. The frontal lobes were destroyed by transverse sections from trephine openings just back of the fronto-parietal suture. Recovery was normal without behavior disturbances. Training was begun 43 days after operation. Learning progressed normally.

Number of trials required for learning.. $\ldots \ldots \ldots \ldots \ldots \ldots \ldots, \mathbf{9 0}$

Per cent of total cortex destroyed..................... 15.5

Lesion: Plate II, figure 16 (17). Both frontal poles were completely severed from the remaining cortex by a transverse section extending

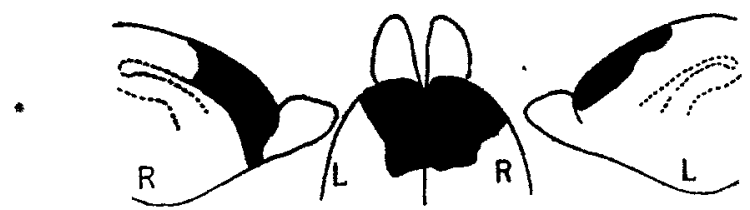

Fig. 7. The Total Extent of the Lesions in animals Whose Records are Shown IN Figure 6

from a point above the knee of the corpus callosum diagonally cephalad to the olfactory tracts. The cerebral nuclei were uninjured.

Number 17. Large female, about 200 days old. The operation was similar to that of number 16 . The animal recovered rather slowly and remained emaciated throughout the experiment. Training was begun 43 days after the operation. Reactions were slow and deliberate. The animal gave evidence of rather rapid learning during the first 40 trials, then developed a stereotyped reaction to the second platform, making sometimes as many as 100 trips to this before going to the first. After 200 trials she made a number of correct reactions, but never succeeded in meeting the requirements of the problem. From the 50th trial on she gave evidence of illness, and by the 250th trial she had become so weak that it seemed best to drop training.

Number of trials required for learning. . $\ldots \ldots \ldots \ldots \ldots \ldots \ldots . \ldots 250+$

Per cent of total cortex destroyed.................... 15.5 
Lesion: Plate II, figure 16 (17). The lesion was identical in every respect with that of number 16 , except that the olfactory tracts were severed, and as the figures for the two brains were practically indistinguishable, only that for number 16 is included in the plate.

One of these two animals learned in normal time, the other failed to learn the problem. The latter is particularly interesting since she is the only animal of the series that failed. Her brain was examined with especial care, but no injury could be found that would account for the inability to learn the problem. The section of the olfactory tracts will not account for the failure, since, as was brought out in the protocol, she learned the second platform very quickly. In all other respects the lesion was so nearly identical with that of number 16 , that the sections could scarcely be distinguished. The animal was ill throughout the experiment and this fact probably accounts for her behavior.

Number 16 learned in normal time after destruction of $\mathbf{1 5 . 5}$ per cent of the cortex, in the region of the frontal pole. The object of the tests was simply to check up the previous observations and a single positive case of learning is sufficient for this. The double-platform box, as well as the simpler inclined-plane box may be learned in the complete absence of the frontal pole of the cerebrum.

Group 6. Frontal and parietal areas destroyed. The object of these operations was to destroy a very large area in the frontal region, including all of the stimulable area. In this respect they were successful, although the lesions were less extensive than I had intended. They include from 24 to 31 per cent of the entire cortex. Descriptions of individual tests follow.

Number 18. Small male, about 150 days old. Large openings were made in the skull over the parietal regions and an attempt was made to destroy all of the frontal and parietal area through these. The animal recovered rapidly, but was very wild and savage for some time after training was begun, 38 days after operation.

Number of trials required for learning.................... 51

Per cent of total cortex destroyed....................... 24.9 
Lesion: Plate II, figure 18. On the right hemisphere a transverse cut completely separated from the rest of the brain all of the cortex lying above the corpus callosum, from the anterior border of the hippocampus to the olfactory fibers at the base of the frontal pole. The latter are uninjured, as are the subcortical nuclei. The lesion of the left hemisphere is similar to that on the right, except that it extends caudad to the middle of the hippocampal lobe.

Number 19. Medium sized female, about 150 days old. The operation was similar to that in the case of number 18. The animal developed a slight right paresis which persisted throughout the experiments. Training was begun 22 days after operation.

Number of trials required for learning $\ldots \ldots \ldots \ldots \ldots \ldots \ldots \ldots 27$

Per cent of total cortex destroyed ..................... 31.8

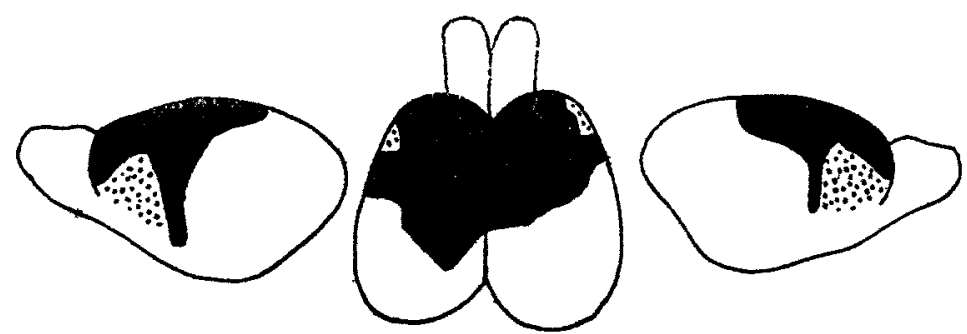

Fig. 8. The Total Extent of the Lesions in animals of Grodp 6 after Operations on the Frontal and Parietal Regions

Lesion: Plate II, figure 19. On the right hemisphere the lesion involved the cortex overlying the corpus striatum and the lateral surface of the frontal pole, to the level of the lateral ventricle. On the left, the lesion included the cortex overlying the corpus striatum, and the latter was also destroyed. The remaining cortex was not degenerated, but the section clearly passed entirely across the frontal pole through the corpora striata and the septum lucidum, and the inclusion in the lesion of all the cortex cephalad to this seems justified.

The records of these animals are included in table 2 . The greater number of trials required is 51 (18), the lesser number is 27 (19). The average is 39 . The average time required per trial on successive days' training is shown in table 3 .

The total extent of the lesions is shown in figure 8. The entire stimulable area and the entire frontal pole were eliminated with- 
out reducing the learning ability of the animals. The greater lesion appeared in number 19 (plate II, figure 19) and this animal required the fewer trials for learning.

\section{Summary of data}

The tests of the learning ability of animals after destruction of areas of the cerebrum cover practically every portion of the cerebral cortex. If we include group 2, every portion is covered but since it might be urged that in hemidecerebrate cases the remaining hemisphere functions normally it seems best to treat of this group separately. The total destruction in all cases except group 2 and number 17 (animal which failed) is shown in figure 9. In these cases, where the destruction was bilateral and nearly

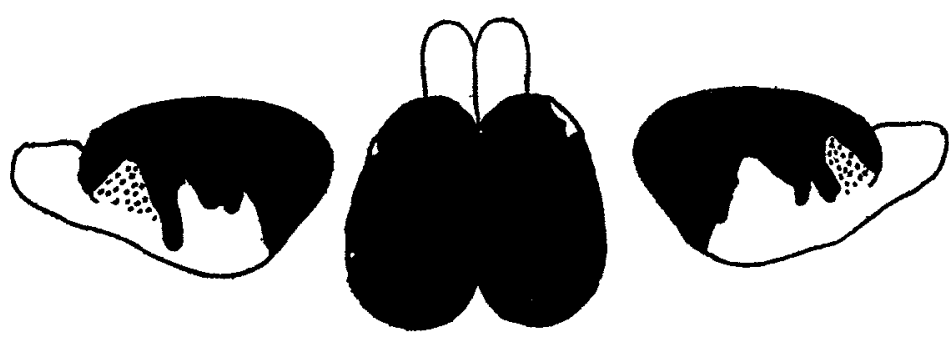

Fig. 9. The Total Extent of Destruction of All Animals Trained on the Dodble-Platform Box, Exclusive of Unilateral Operations

symmetrical, all of the frontal, dorsal, and occipital region has been destroyed and there remains only a small basilar region which has not yet been explored. I have made many attempts to produce injuries restricted to this area, both by dissection and by injection of chemicals, but the operations have always been attended by hemorrhage around the medulla which resulted fatally. However, the region is thoroughly covered by one of the hemidecerebrate cases and this, with the results which have attended operations on other portions of the cerebrum make it practically certain that this unexplored area is of no greater importance for learning than is any other part of the cerebrum.

The numbers of trials required for learning and the extents of injury to the cerebrum in each animal studied in these experi- 
ments are summarized in table 4. The average numbers of trials required for learning by the members of each group are included in table 2. From these two tables it is evident that the operated animals were not at all inferior to normal ones trained under the same conditions. Indeed, as the data stand, it seems that the operated animals are much superior to the normal controls. The average number of trials required by the normal ani-

TABLE 4

The number of trials required by operated animals for learning the double-platform box, with the percentage of the total cerebral cortex injured

\begin{tabular}{|c|c|c|c|c|}
\hline NULBER & TRIALS & $\underset{\text { INJURY }}{\text { PER CENT }}$ & LESION & BEBAVIOA \\
\hline 1 & 141 & 27.0 & Hemidecerebrate & Normal \\
\hline 2 & 132 & 40.7 & Hemidecerebrate & Normal \\
\hline $\mathbf{3}$ & 54 & 50.0 & Hemidecerebrate & Hemiparesis \\
\hline 4 & 75 & 42.4 & Hemidecerebrate & Slight left paresis \\
\hline 5 & 72 & 26.6 & Hemidecerebrate & Marked right paresis \\
\hline 6 & 49 & 30.4 & Hemidecerebrate & Slight right paresis \\
\hline 7 & * 107 & 32.1 & Occipital injury & Normal \\
\hline 8 & 97 & 17.8 & Occipital injury & Normal \\
\hline 9 & 45 & 40.8 & Occipital injury & Cage bully \\
\hline 10 & 82 & 20.3 & Occipital injury & Normal \\
\hline 11 & 101 & 21.2 & Parietal injury & Normal \\
\hline 12 & 81 & 15.2 & Parietal injury & Normal \\
\hline 13 & 41 & 31.5 & Parietal injury & Normal \\
\hline 14 & 99 & 29.3 & Parietal injury & Slight right paresis \\
\hline 15 & 78 & 14.2 & Parietal injury & Normal \\
\hline 16 & 90 & 15.5 & Frontal injury & Normal \\
\hline 17 & 250 & 15.5 & Frontal injury & Ill \\
\hline 18 & 51 & 24.9 & Entire motor area & Wild \\
\hline 19 & 27 & 31.9 & Entire motor area & Right hemiparesis \\
\hline
\end{tabular}

mals is 142.6. The average number required by all operated animals (exclusive of number 17) is 79. The difference is 63.6 trials in favor of the group with injury to the cerebrum, or 44.6 per cent.

In this respect the experiment seems to prove too much! Had such a difference appeared in the other direction we might have been inclined to accept the result without question as indicating a significant retarding effect of cerebral injury upon the learn- 
ing process. But we can not accept as readily the view that cerebral injury results in an improvement in learning ability. What, then, is the cause of the difference between the normal and operated groups? The first explanation suggested is that the problem box used in some way favored the injured animals.

Observation of the animals during training indicates that the double-platform box does so favor the operated animals. When the normal rat encounters a low obstacle in his path he is very apt to jump over it. In some preliminary tests the platforms used were only $2 \mathrm{~cm}$. broad. Normal animals failed to learn the problem in this form because they almost invariably jumped over the platforms and so failed to trip the latches. Platforms $5 \mathrm{~cm}$. in width were then substituted for the narrower ones and with this modification the normal animals were able to learn the problem, although they still frequently leaped over the platforms. During the experiments with the operated animals I gained the impression that they leaped the platforms less frequently than normal animals, but did not collect statistics on the point. A crucial test of it is furnished, however, by a comparison of the learning rates of paretic animals with those of the remainder which showed no motor disturbance. The averages of paretic and non-paretic animals are the following:

Trials for learning

Paretic animals required $\ldots \ldots \ldots \ldots \ldots \ldots \ldots \ldots \ldots \ldots \ldots, 62.6$

Non-paretic animals required $\ldots \ldots \ldots \ldots \ldots \ldots \ldots \ldots \ldots \ldots \ldots \ldots, 87.1$

From this it appears that a definite paresis is advantageous for learning the problem. Animals with motor disturbance are more apt to trip the catches by chance than those without, and they therefore have a better chance to learn. A part of the apparent superiority of the operated animals may thus be ascribed with certainty to a lack of vigor. But how much of the total difference between normal and operated animals is due to this? The data at hand do not permit of a certain answer to the question, but various lines of evidence point to the conclusion that irrelevant factors at least did not change a real inferiority of the operated animals into an apparent superiority: that the normal and operated groups are most probably equal in learning ability. 
The time required for solving the problem in successive trials during training by the animals in the different groups is summarized in table 3 . Some of the animals learned the problem quickly and training was discontinued with them soon afterward. If their records are dropped out at the point where they finished practice the end of the learning curve will represent, not the average for the group, but the average of only those animals which learned slowly. To avoid this the time for the perfect records of each animal that finished early is included in the computation of the average for each period of later training with the group.

Judged by the time alone, the normal animals are somewhat superior to the operated ones, yet the superiority is by no means significant until after the fiftieth trial.. The normal animals were but slightly superior to groups 3 and 5 in the time required for the perfect records (last period of training) and never equaled the record of group 4. Time records alone are probably never an accurate measure of the rate of learning and in this case they are apt to be particularly misleading since some of the paretic animals moved slowly throughout the experiments and, even when they made fewer errors, consumed more time than the normals.

The time records, then, give no accurate measure of the relative abilities of the groups. They do show roughly, however, that there is no very significant difference in rate of learning between the normal and operated animals.

The use of the problem box permits of a certain amount of variation in the standard of perfection required. Errors were recorded when the rat deviated from his usual path, but a good bit of latitude was allowed in the choice of that path. He might go in front of, across the top of, or behind the problem box in passing from platform $a$ to $b$. So long as a stereotyped path was followed, learning was considered perfect. This allows some chance for the personal equation of the experimenter to modify the results. A partial check upon this source of error is provided by experiments upon the rate of formation of a habit of visual discrimination in which a definite invariable standard of error could be adopted. A description of this experiment follows. 
The formation of a visual habit

Methods. Seven normal and four operated animals were trained in a habit of brightness discrimination and their rates of learning compared. The apparatus used was a simple Yerkes' discrimination box (previously used and figured by Dodson, '17) offering the choice of an illuminated and a dark alley, food being given with the light and no food with darkness. If the animal

\section{TABLE 5}

The average percentage of errors made by normal animals and by animals after injury to the frontal pole of the cerebrum during successive days' practice in forming a habit of visual discrimination. The averages are based on seven normal and three operated animals trained under uniform conditions with ten trials per day

\begin{tabular}{c|c}
\hline \multicolumn{2}{c}{ PER CENT RRROR } \\
\hline Normal & Operated \\
\hline 61.8 & 73.3 \\
52.3 & 50.0 \\
42.7 & 66.6 \\
30.0 & 30.0 \\
18.6 & 30.0 \\
24.3 & 26.6 \\
14.3 & 13.3 \\
7.2 & 3.3 \\
5.7 & 3.3 \\
11.4 & 3.3 \\
5.7 & 0.0 \\
1.4 & 0.0 \\
5.7 & \\
0.0 & \\
0.0 & \\
\hline
\end{tabular}

entered the darkened alley an error was recorded. Training was continued with 10 trials per day until 20 successive trials were made without error. Records of the animals follow.

Normal animals. The seven normal animals required an average of 106.6 trials for learning, not including the final 20 trials without error, with a range from 60 to 130 . Details of their records will be given in another paper. Their daily averages are given in table 5 . 
Operated animals. Four animals were trained after destruction of the frontal pole of the cerebrum. Three of them finished training and only limitation of time prevented the fourth from learning the problem. Their individual records are given below.

Number 1. Small female, 94 days old. The frontal pole of the cerebrum was injured by a transverse incision carried diagonally forward from the fronto-parietal suture. Training was begun 72 days after operation. She became ill during the latter part of training and had to be given a week's rest with full allowance of food.

Trials required for learning......................... 100

Lesion: Plate III, figure 1. The frontal poles of both hemispheres, between and in front of the forceps of the callosum were completely destroyed.

Number 2. Small female, 94 days old. The frontal pole of the cerebrum was injured as in the case of number 1. Training was begun 72 days after operation.

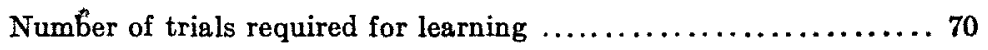

Lesion: Plate III, figure 2. Practically all of both hemispheres in front of the vertical plane of the knee of the corpus callosum was destroyed. The left olfactory tract was severed. Both corpora striata were injured, that on the left most extensively.

Number 3. Small female, 73 days old. Operation as in the case of number 1. Training was begun 72 days after operation.

Number of trials required for learning. 70

Lesion: Plate III, figure 3. All of the cortex lying above and between the forceps of the callosum was completely destroyed. The subcortical ganglia were uninjured.

Number 4. Medium sized male, 150 days old. Both frontal lobes were destroyed by transverse incisions. Recovery was very slow. The animal lay for four days in coma and appeared to be stuporous up to the beginning of training, 60 days after operation. During training he was very erratic, trying to climb out of the training box, or lying quiet for long periods. After 30 trials, however, he gave certain evidence of discrimination, turning back repeatedly before he reached the end of the dark alley, when errors were made, and advancing into 
the illuminated alley with a rush. Training was continued for only 50 trials, which did not permit of perfecting the habit but the secondary evidence of discrimination is conclusive.

Lesion: Plate III, figure 4. The frontal poles of both hemispheres in front of and above the knee of the corpus callosum were completely severed from the remainder of the brain, by an incision which passed through the olfactory tracts.

The total extent of the lesion in these animals is shown in figure 10. The average percentage of errors made on successive days by the normal and operated animals in these experiments is given in table 5. There is no very marked difference in the amount of improvement shown by the two groups from day to day.

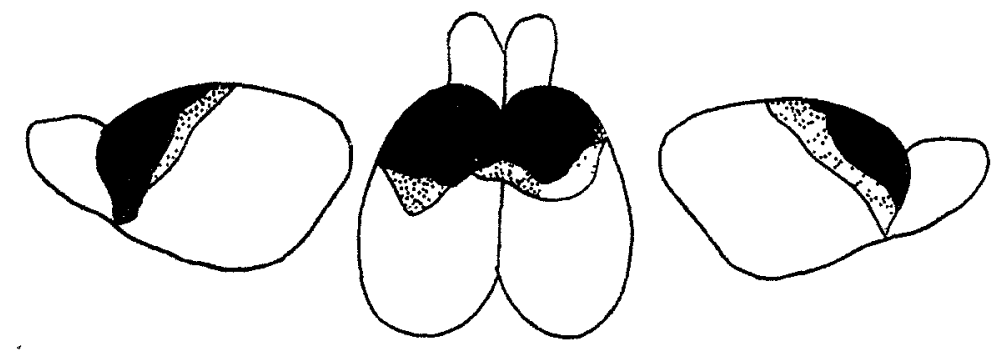

Fig. 10. The Total Extent of the Lesions in Animals which Formed the Habit of Visual Discrimination after Operation

The stippled area represents the animal with which training was not completed.

The average number of trials required by the normal animals for learning the visual habit was 106.6 with a range from 60 to 130. The average number required by the operated animals was 80 , with a range from 70 to 100 . The operated animals thus show a superiority of 26.6 trials, or 24.9 per cent, over the normal animals. As in the experiments with the double-platform box, the operated animals are superior in learning ability to the normal controls.

In this case, however, the explanation offered before for the superiority of the operated animals does not hold good. The discrimination habit does not seem to be influenced by the relative activity, or vigor, of the animals and the use of a constant 
criterion of error effectively eliminates the personal equation of the experimenter. Are we then to conclude that the removal of a portion of the cerebrum does improve ability to learn? Such a conclusion seems preposterous, but there is no evidence at present from which $I$ can deduce the flaw in the experiments. It is most probable that the difference between the groups is merely a chance result which would not hold if a larger number of cases were studied.

From the test it seems clear, at least, that the operated animals are able to learn as readily as do normal ones. The experiments have failed to reveal any retardation of the learning process resulting from the removal of the anterior third of the cerebrum.

The effects of destruction of deep-lying structures

The more important cerebral structures which lie below the surface and which might play some part in learning are the corpora striata, the hippocampal lobes, and the corpus callosum. Many of the animals trained on the double-platform box show extensive destruction of these structures and make it possible to test their function in learning.

The animals showing injuries to the hippocampal lobes were:

Number 5. Left hippocampal lobe injured.

Number 6. Left hippocampal lobe extensively injured.

Number 7. Right hippocampal lobe replaced by a cyst.

Number 8. Both hippocampal lobes slightly injured.

The average number of trials required for learning by these four animals was 81.2 , which is practically the same as the average for all operated animals. The hippocampal lobes are not more important for learning than other parts of the cortex.

The animals showing injury to the corpora striata are:

Number 3. Complete destruction of the left C. S.

Number 4. Extensive injury to the right C. S. with probable interruption of its connections with the thalamus.

Number 5. Probable section of the connection of the left C.S. with the thalamus. 
Number 6. Complete destruction of the left C. S.

Number 13. Superficial injury to the right C. S.

Number 19. Severe injury to the left C. S., slight injury to the right.

The average number of trials required for learning by these animals was 53.0 which is slightly less than the average of paretic animals (most of them were paretic). The corpora striata are not of greater importance for learning than other parts of the cortex.

It has been claimed that injury to the corpus callosum results in some deterioration. Since the experiments have shown that the destruction of an entire hemisphere does not retard learning, the interruption of commissural fibers can hardly have a different effect. Actual test of this is provided by animals number 11, 14 , and 18 which showed a very nearly eomplete destruction of the corpus callosum with cysts exposing the lateral ventricles. The average number of trials required for learning by these three animals was 83.6 , which is not significantly greater than the average of all.

These records show that the structures mentioned have no special function in learning. In the various tests practically every deep-lying structure above the thalamus was injured and it seems clear that none of the cerebral nuclei is of any greater importance for learning than is the pallium.

IV. THE RELATION OF THE RATE OF LEARNING TO THE AMOUNT OF CEREBRAL INJURY

The apparent superiority of the operated animals in the foregoing experiment raises again the question of the real significance of the data obtained with the double-platform box and with the inclined-plane box in earlier work. Further evidence upon the point is furnished by a study of the relation of the rate of learning to the amount of cerebral material removed. This relation is of considerable interest from other standpoints also. If, as seems to be the case, there is no specialization of cerebral function for the acquirement of habits, learning may be the result either of 
the mass action of the cerebrum, as held by Loeb ('00) or of the formation of new functional reflex connections through any part of the cortex which happens to be intact. If the first assumption is correct, destruction of large areas of the cerebrum should retard learning more than lesser destructions.

The problem has been raised in a somewhat different way by the apparent reduction in learning ability of human defectives who show a deficiency in the cells of the pyramidal layer (Bolton, '05). The present evidence bears only indirectly upon this condition but it does seem that if deficiency in learning results from a reduction of the number of functional cells in one cortical layer it should also result from a reduction in the total number of cells, provided all are destroyed in like proportions.

To determine the percentage of the cortex destroyed by the various operations the total area of the cortex shown on the diagram used in plates I and II was measured. The area of the plotted lesions was then determined and, after correction for overlapping of the dorsal and lateral figures, was expressed as a percentage of the total area. This method gives only a rough measure of the extent of the lesion. As an absolute measure of the area destroyed it would be quite misleading, but since the same method was employed for all the data, it seems to give comparable figures for the different brains. The per cent of the total area of the cortex destroyed in each animal is given in table 6 , ranked from the least to the greatest, together with the number of trials required for learning by each animal.

The average amount of destruction in all animals is 28.4 per cent. The average number of trials required for learning by all the animals with less than this amount of destruction is 88.1. The average number of trials required by those with more than the average destruction is 69.9 . This gives a difference of 18.2 trials, or 20.6 per cent, in favor of the animals with the greater injury. But this analysis includes the animals with paresis (table 4). If we exclude them the averages become: for the group with less than average destruction, 82.8 trials, for the group with greater than average destruction, 93.2 trials, a difference of 11.1 per cent in favor of the group with lesser injury. 
This result is due, however, solely to the position of animal number 1 , which showed average destruction and slow learning. If he is included with the lower group the relations are reversed to 10 per cent in favor of the group with greater destruction.

We may conclude, therefore, that the differences here are not significant. Paresis gives the animal a slight advantage in learning the double-platform box, but aside from this the extent of injury does not affect the rate of learning. Amounts of injury from 14 to 50 per cent of the entire cerebral cortex do not result in any correlated alteration in the animals' learning ability.

\section{TABLE 6}

The relation of the quantity of cerebral cortex destroyed to the rate of learning in animals trained on the double-platform box. On the left are the animals with less than the average destruction, on the right those with more than the average

\begin{tabular}{|c|c|c|c|c|c|}
\hline $\begin{array}{l}\text { PER CENT OF } \\
\text { CORTEX } \\
\text { DERTROY }\end{array}$ & $\begin{array}{l}\text { TRIALA FOR } \\
\text { LEARNING }\end{array}$ & $\begin{array}{l}\text { NUMBER OF } \\
\text { ANIMAI }\end{array}$ & $\begin{array}{l}\text { PER CENT OF } \\
\text { CORTEX } \\
\text { DEATROYED }\end{array}$ & $\begin{array}{l}\text { TRIAIS FOR } \\
\text { LEARNING }\end{array}$ & $\begin{array}{l}\text { NUMBRR or } \\
\text { ANIMAL }\end{array}$ \\
\hline 14.2 & 78 & 15 & 29.3 & 99 & 14 \\
\hline 15.5 & 90 & 16 & 30.4 & 49 & 6 \\
\hline 15.2 & 81 & 12 & 31.5 & 41 & 13 \\
\hline$(15.5)$ & Failed & (17) & 31.9 & 27 & 19 \\
\hline 17.8 & 97 & 8 & 32.1 & 107 & 7 \\
\hline 20.3 & 82 & 10 & 40.7 & 132 & 2 \\
\hline 21.2 & 101 & 11 & 40.8 & 45 & 9 \\
\hline 24.9 & 51 & 18 & 42,4 & 75 & 4 \\
\hline 26.6 & 72 & 5 & 50.0 & 54 & 3 \\
\hline 27.0 & 141 & 1 & & & \\
\hline Averages 20.3 & 88.1 & & 36.6 & 69.9 & \\
\hline
\end{tabular}

None of this evidence really settles the question of the significance of the apparent superiority of the operated animals over normals. The data on paretic animals and on the relation of the extent of the injury to the rate of learning do suggest, however, that the reduction in vigor is the chief cause of the difference and also give some indication of the actual extent to which such reduction has influenced the results. The existence of an observable paretic condition is able to produce a superiority of 28 per cent over the learning rate of non-paretic operated animals (page 92). The difference in vigor between the non-paretic 
operated animals and normals is much less than between paretic and non-paretic and it is therefore very unlikely that it could have resulted in an acceleration of learning of more than 39 per cent, which is the difference found between non-paretic operated and normal animals. It can not, therefore, have altered a significantly reduced ability to learn into an apparent heightened ability. At most, it can only have obscured an actual equality. The evidence from the time consumed in training also fails to reveal a marked inferiority of the operated animals and there is a seeming equality in learning ability between animals with great and with small lesions.

All the data then seem to point toward an equality of normal and partially decerebrate animals with respect to learning ability. Certainly there is no evidence to show that the injuries to the cerebrum resulted in any reduction of the power to learn.

\section{The bearing of the experiments on cerebral function in learning}

The interest of the experiments lies, after all, not so much in the comparative rates of learning of normal and partially decerebrate animals as in the fact that the animals can learn at all rapidly after such extensive brain injuries. And on this point the experiments are absolutely conclusive. They have covered every poption of the cerebrum in one or another animal, and with bilateral operation every region except a small area at the base of the temporal lobes (figure 9). No single part of the cerebrum has proved to be necessary for the learning of the double-platform box and no single part has proved to be significantly more efficient in learning than any other part. For the acquirement of the habit the various parts of the cerebrum seem to be absolutely equipotential. Moreover, at least 50 per cent of the cortex can be dispensed with without marked deterioration and there seems to be no relation between the absolute quantity of cerebral cortex functional and the ability to learn.

Whether greater injury than 50 per cent would cause deterioration has not been determined. I have made some attempts to produce greater lesions but have not yet developed a satisfactory 
technique. In previous work Dr. Franz and the writer obtained formation of simple habits after somewhat more extensive injuries but unfortunately these animals were not tested in a more difficult habit.

What is the bearing of these results upon the problem of the cerebral mechanism of learning? "In the first place, they show conclusively that there are in the rat no special association areas to which is restricted the function of associating sensory and motor projection areas. We know from earlier work that habits of the type required by the double-platform box are normally mediated by the frontal pole. But in the absence of this some other part assumes its function. The same condition must be true for any other so-called association area that may exist in the rat's cortex. There may be association areas which can function alternatively, but the operations have covered almost all combinations of cerebral regions except bilateral frontal with occipital and this possibility seems almost ruled out.

Second, the work of Franz on cats and monkeys and of Franz and the writer on the rat indicates that the cerebral reflex paths functioning in certain habits are distributed uniformly to all parts of the frontal region, since the destruction of one frontal lobe in the higher forms or of any given part of the frontal pole in the rat is not followed by loss of the habit and the destruction of the entire frontal region does result in loss of the habit.' The present experiments indicate, further, that the organization of the entire cerebrum of the rat must be along similar lines; that the reflex connections involved in habits may be laid down in any part of the cortex. Under normal conditions the frontal pole perhaps offers less resistance to the reintegrating of the activities required by the habit than do other parts, but the same integrations may be formed readily elsewhere.

The determination of the regions which actually did function in the habit would have been of considerable interest. Franz found that when the animal lacking the frontal lobe learned a problem box, destruction of tissue adjacent to the first injury resulted in loss of the habit. On the other hand, Leyton and Sherrington ('17) failed to locate the region which assumed motor 
control of the thumb in the chimpanzee after the normal area had been destroyed. They did determine that the function was not taken up by adjacent areas. It would have been possible to make such determinations in the present series by operating subsequent to training but a second operation makes it difficult to delimit the first lesion exactly and it seemed best to restrict the present work to the investigation of the vicarious functioning of the cerebrum and to postpone the working out of the exact areas functioning to a later time.

Third, the existence of a special area for attention or for "higher psychic functions" is ruled out. If there is any difference, the operated animals show somewhat more definite limitation of behavior to reactions to the problem situation than do normals and the double-platform box certainly demands "intelligence" if we can use the term in reference to any animal.

Finally, the experiments raise another question of fundamental importance. What becomes of the concept of sensory and motor projection areas if the entire cerebral cortex of the rat is equipotential in learning? The following sections of this paper record an attempt to answer this question.

V. THE FUNCTION OF THE CEREBRUM IN THE RETENTION OF A HABIT OF VISUAL DISCRIMINATION

The formation of the double-platform box habit involves at least the linking up of tactile and kinaesthetic impulses with motor reactions. Other sense organs probably play only a minor rôle. We do not know the position of the kinaesthetic projection area in the rat, but it probably has some such position as in the cat (Barenne, '16) where it seems to be not clearly separated from the motor area. Whatever its position, if it is definitely localized, it was certainly destroyed in some of the experiments, yet none of the animals gave evidence of loss of kinaesthetic impulses. The exact function of these in the behavior of the rat is difficult to determine, however, and it seemed desirable to have data on learning involving some stimulus which can be experimentally controlled, in order to determine whether there are 
definite areas corresponding to the sensory projection areas of higher forms and what the relation of these to habit-formation may be.

Such data will be of value also for the elucidation of another problem. In his work on the frontal lobes Franz was inclined to take the view that they acted as an association area, that they were functional in learning because it was learning and not merely because they are the normal projection areas for some group of afferent or motor impulses. His experiments dealt only with various types of latch-boxes, the habits for all of which probably have a kinaesthetic foundation. If his view is correct, the destruction of the frontal lobes should result in the abolition of any complex, recently formed habit. If, on the contrary, the frontal lobes serve simply as a projection area, some sensory habits should be found which would survive their destruction and be eliminated by injury to other parts.

With these questions in mind I took up the study of a visual habit; discrimination between light and darkness.

\section{Apparatus and methods}

For setting up the habit a Yerkes' discrimination box of the customary form was used. (The particular box has been figured by Dodson, 'I7). The box offers a choice of two alleys and at the end of each alley a circular, translucent stimulus plate was fixed. In each trial one of these was illuminated, the other dark. A number of normal animals were trained to go toward the illuminated plate and to avoid the dark one. No attempt was made to restrict the stimulus to the plates and it is probable that the animals reacted to the general illumination of the alleys (Lashley, '12). Precautions were taken, however, to insure that the reaction was to the visual stimulus. I have discussed the control of visual stimuli extensively in other papers ('12 and '16) and need not review the controls here.

The animals were given 10 trials per day (food with the positive, no food with the negative stimuli) and training was continued until errorless records were obtained on two successive 
days, a total of 20 successive errorless trials. Entrance into the darkened alley was counted as an error.

Since the operation entails a period of from one to five days without practice it was necessary to determine the loss of the habit which this rest alone would produce. Therefore, when each animal had learned the problem he was kept for seven days without practice and was then tested for retention of the habit. These tests are recorded as "preliminary retention tests" in the records of experiments. In case a loss of habit appeared after this rest periód the animal was retrained until he made 20 successive errorless trials. When these were completed he was subjected to operation.

For the experiments the animals were divided into four groups. The number of animals in each group and the character of the

TABLE 7

Distribution of animals in experiments on discrimination of brightness

\begin{tabular}{|c|c|c|}
\hline GROUP & CHARACTER OF LESION & $\begin{array}{l}\text { NUMBER } \\
\text { OF } \\
\text { ANIMALB }\end{array}$ \\
\hline 1 & Frontal pole destroyed $\ldots \ldots \ldots \ldots \ldots \ldots \ldots \ldots \ldots \ldots$ & 2 \\
\hline 2 & Parietal regions destroyed.$\ldots \ldots \ldots \ldots \ldots \ldots \ldots \ldots$ & 2 \\
\hline 3 & Skull opened in occipital region, no injury ............. & 1 \\
\hline 4 & Occipital regions destroyed $\ldots \ldots \ldots \ldots \ldots \ldots \ldots \ldots$ & 3 \\
\hline
\end{tabular}

operation are shown in table 7. As soon as they had recovered from the shock of operation, in from 24 to 96 hours, they were tested in the discrimination box for evidence of retention. At least 30 trials were given in the postoperative retention tests. Two sorts of evidence are important in interpreting the results. First, the postoperative retention tests may show no more error than the preliminary retention tests. They then give conclusive evidence of retention. Second, when the postoperative retention tests show numerous errors the animal may yet give evidence of retention by selective reactions to the stimuli.

At one stage in the formation of a visual discrimination habit the rat begins to give evidence of attention to the lights. The first trials are evidently random dashes and in case of a wrong choice the rat does not turn back until he has actually been pre- 
vented from reaching the food. At a later stage he hesitates before choosing an alley, advances toward the negative stimulus hesitatingly and turns back before he reaches it. Later he may stand at the entrance to the two alleys and sway back and forth between them, finally choosing the positive stimulus. Such behavior is easily recognizable and is the invariable precursor of accurate discrimination. In the following records it is referred to as "comparison-movements."

After the postoperative retention tests the animals were killed and their brains examined in serial sections. The records of the separate tests follow.

Group 1. Frontal pole of cerebrum destroyed.

Number 5. Small male, 109 days old. Trained on brightness discrimination.

Number of trials required for learning.................... 100

Preliminary retention tests, per cent error... $\ldots \ldots \ldots \ldots \ldots \ldots, 4$

The frontal pole of the cerebrum was injured by transverse incision. On the following day the animal was very weak, scarcely able to reach the food, but his reactions were unhesitating, with comparison movements. Only one error was made in ten trials. On the second day he was stuporous and was not tested. On the third day his reactions were quick and discrimination was unmistakable.

Postoperative retention tests, per cent error.

Lesion: Plate III, figure 5. Both frontal poles were completely destroyed by a section passing diagonally forward from the frontoparietal suture along the forceps of the callosum to the base of the olfactory bulbs.

Number 6. Small male (castrated), 108 days old. Trained in brightness discrimination.

Number of trials required for learning ... . . . . . . . . . . . . 50

Preliminary retention tests, per cent error................ 5

Operation was as in the case of number 5. On the day following operation his reactions were quick. One error was made in ten trials with comparison-movements and negative reactions to darkness Later trials verified the first day's record. 
Lesion: Plate III, figure 6. The dorsal convexity of both frontal poles was completely destroyed.

Both these animals gave certain evidence of discrimination within 24 hours after the operation. In both the frontal pole was completely destroyed. They had not been overtrained, so that there is no reason to believe that a once cortical habit had been reduced by practice to lower levels. It is probable that the frontal pole of the cerebrum is not functional either in the formation or the retention of the habit of visual discrimination.

Group 2. Parietal regions destroyed.

Number \%. Small male, 130 days old. Trained in brightness discrimination. Was always erratic and given to exploration.

Number of trials required for learning................. 220

Preliminary retention tests, per cent error ............... 7.5

The parietal areas of both hemispheres were injured by incision through two trephine holes extending backward from the fronto-parietal suture. Retention was tested on the following day. He was then excited and restless, his reactions were quick, but showed an exploratory character, an exaggeration of his previous behavior. On the second day he was stuporous and was not tested. On the third and later days he made no error and gave secondary evidence of perfect discrimination.

Postoperative retention tests, per cent error................ 0

(After first day)

Lesion: Plate III, figure 7. The central portion of the convexity of both hemispheres was replaced by cysts. The degenerated cortex extended from the knee of the corpus callosum caudad to the anterior margin of the hippocampus, laterad from the longitudinal sinus to the orbital surfaces.

Number 8. Small male (castrated), 115 days old. Trained in brightness discrimination.

Number of trials required for learning $\ldots \ldots \ldots \ldots \ldots \ldots \ldots \ldots, 60$

Preliminary retention tests, per cent error................. 2.5

Operation was as in the case of number 7. Retention was tested on the day following operation. For several days after operation the rat's 
right eye was closed. On the first day he seemed to discriminate correctly whenever, in starting, his left eye was directed toward the illuminated alley. There was a marked tendency to circus movements towards the functional eye. On the second day he was not tested. On the third and later days he made no errors and there was unmistakable secondary evidence of discrimination.

Postoperative retention tests, per cent error $\ldots \ldots \ldots \ldots \ldots \ldots \ldots, 20$

After first day....................................... 0

Lesion: Plate III, figure 8. The lesion is almost identical with that of number 7 , but more complete in the mesial region.

After destruction of the greater part of the parietal and orbital regions these animals gave good evidence of the retention of the discrimination habit. If we disregard the records of the first day (24 hours after operation) when both animals were in an abnormal condition, we find that they showed perfect retention. Like the frontal pole, the parietal and orbital regions are not functional in the visual habit.

Group 3. Occipital control. To determine whether or not the shock of operation in the occipital region would produce loss of the habit, irrespective of injury to the brain, I trephined the skull in one animal in the region through which the occipital operations were to be performed.

Number 9. Small male (castrated), 115 days old. Trained in brightness discrimination.

Number of trials required for learning 60

Preliminary retention tests, per cent error.................... 2.5

Two openings were made in the skull about two millimeters in front of the parieto-occipital suture, similar to those through which operations on the occipital lobes were performed in other animals. The brain was left with no other injury than that occasioned by opening the skull. Retention was tested on the following day. Reactions were prompt and without error. His behavior was quite uninfluenced by the operation.

Postoperative retention tests, per cent error................. 0

Lesions: Plate III, figure 9. Except for adhesions in the area of the trephine holes the brain was uninjured. 
This animal showed perfect retention after operation. Opening the skull in the occipital region does not produce sufficient shock to cause loss of the habit.

Group 4. Occipital region destroyed.

Number 10. Small male, 114 days old. Trained in brightness discrimination.

Number of trials required for learning ... . . . . . . . . . . . . 60

Preliminary retention tests, per cent error................ 2.5

The occipital lobes were injured by passing a knife backward from openings in the skull, like those in number 9 , to the base of the skull, avoiding injury to the thalamus and cerebellum. Retention was tested on the following day. The animal was active and gave little evidence of discomfort. He went through the problem box promptly and without hesitation. He found the food readily and corrected his errors promptly, but he made six errors in ten trials. On the following day his behavior was like that of an animal in the early stages of training. He retained all of the habits of the discrimination box except that of visual discrimination. Retraining was begun and for four days he gave no evidence of discrimination. He then improved until the reaction was reestablished.

Postoperative retention tests, per cent error............... 50

Trials required for relearning $\quad \ldots \ldots \ldots \ldots \ldots \ldots \ldots \ldots \ldots . \ldots \ldots$

With errors distributed on successive days as follows.........

$$
6,5,5,3,3,0,1,0,2,2,0,0
$$

Lesion: Plate III, figure 10. On the left the lesion included all of the cortex caudad to the plane of the posterior limit of the hippocampus. On the right the mesial surface of the occipital lobe remained intact.

Number 11. Small male, 107 days old. Trained in brightness discrimination.

Number of trials required for learning $\ldots \ldots \ldots \ldots \ldots \ldots$

Preliminary retention tests, per cent error $\ldots \ldots \ldots \ldots \ldots \ldots \ldots .2 .5$

The occipital lobes were injured by an operation similar to that on number 10. Retention was tested on the day following operation. The animal was very active, extremely hungry, and when he reached the food ate voraciously. He seemed unable to adjust himself to making the turn into the food compartment and after the fourth trial 
persisted in climbing out of the discrimination box. On the second day he responded promptly and found the food readily, but developed a position habit which persisted for three more days. Training was continued until he relearned the problem.

Postoperative retention tests, per cent error $\ldots \ldots \ldots \ldots \ldots \ldots \ldots 65$

Number of trials required for relearning $\ldots \ldots \ldots \ldots \ldots \ldots \ldots \ldots .74$

With errors distributed on successive days as follows

$$
3 \text { (of } 4), 6,4,9,2,0,3,4,0,0
$$

Lesion: Plate III, figure 11. On the right hemisphere the lesion passed through the dorsal surface of the hippocampus and included all the cortex laterad and caudad to this structure. On the left hemisphere the lesion was less extensive and included only the cortex dorsad and caudad to the hippocampus.

Number 12. Small male, 115 days old. Trained in brightness discrimination.

Number of trials required for learning................6 60

Preliminary retention tests, per cent error $\ldots \ldots \ldots \ldots \ldots \ldots, 0.5$

The occipital regions were destroyed as in other cases. Retention was tested on the following day. He found the food readily and corrected his errors promptly, averaging less than two seconds per trial. During 60 trials on six successive days he gave no evidence of visual discrimination. Retraining was not undertaken.

Postoperative retention tests, per cent error 55

Lesion: Plate III, figure 12. The dorsal convexity of both occipital poles was destroyed.

These three animals after extensive destruction in the occipital region showed complete loss of the habit of visual discrimination. Evidently the visual habit is mediated in some way by the occipital region and by the occipital region alone. Two of the three animals relearned the habit in normal time; the third was not tested adequately. The occipital lobes, though normally functional, are not necessary for the formation of the visual habit. 


\section{Summary and discussion}

The total extent of the injuries in the frontal and parietal regions (animals, 5, 6, 7, and 8) is shown in figure 11. Practically all of the anterior two-thirds of the cerebrum was covered by these tests. The animals all gave unmistakable evidence of retention of the habit and the slight reduction in accuracy in some cases is no more than would be expected from the general systemic results of the operation.

The experiments reported on page $94 \mathrm{ff}$. show that the frontal regions of the cerebrum are not necessary for visual discrimination. These experiments show, in addition, that the perfected habit of visual discrimination is not mediated by the frontal,

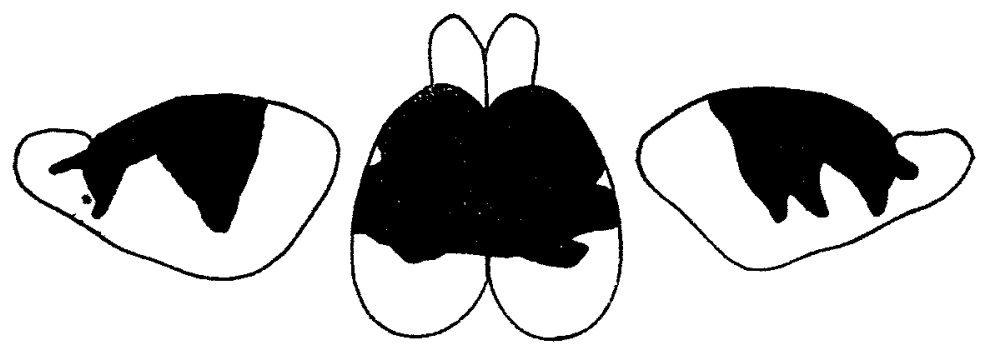

Fig. 11. The Total Extent of Lesions in antmals Which Retained the Habit of Visual Discrimination after Operation

parietal, or orbital surfaces of the cerebrum, and that these areas probably have no part in its normal formation.

The last three cases give equally clear evidence that the occipital pole is intimately concerned with habits of visual discrimination. Table 8 gives their retention records in comparison with the others. Every one of the animals lost the habit completely after injury to the occipital pole. That the loss was due to cerebral destruction and not to the mere shock of operation is indicated by the results with number 9 , and by the fact that equally extensive operations in other regions adjacent to this produced no disturbance in behavior.

These data justify the conclusion that the entire cortical mechanism of the perfected visual habit is included within the 
occipital pole of the cortex. This is not at all in accord with current views concerning the mechanism of habit-formation. Von Bechterew ('11, p. 2020) has summarized the more commonly accepted view in these words:

Since from earlier observations in my laboratory (Dr. Protopopov) it appeared clearly that in the production of the association reflex the motor reaction is mediated through the motor cortex and the perception of the associated stimulus occurs in the cortical perceptual or socalled sensory centers (at least for sound, light, and contact) whose localization is now well known, it follows that the excitation of the motor reactions is induced by association fibers which must connect these perceptual or sensory centers with the motor area.

TABLE 8

The percentage of errors made by animals tested for retention of the habit of brightness discrimination before and after cerebral operation

\begin{tabular}{|c|c|c|c|}
\hline \multirow[b]{2}{*}{ NUMBER } & \multirow[b]{2}{*}{ CEARACTER OF LEBSION } & \multicolumn{2}{|c|}{ PER CENT ERROR } \\
\hline & & $\begin{array}{c}\text { Preliminary } \\
\text { retention } \\
\text { tests }\end{array}$ & $\begin{array}{l}\text { Postoperative } \\
\text { retention } \\
\text { tests }\end{array}$ \\
\hline 5 & Frontal................ & 4 & 10 \\
\hline 6 & Frontal $\ldots \ldots \ldots \ldots \ldots \ldots \ldots \ldots \ldots \ldots$ & 5 & 10 \\
\hline 7 & Parietal. $\ldots \ldots \ldots \ldots \ldots \ldots \ldots \ldots$ & 7.5 & 0 \\
\hline 8 & 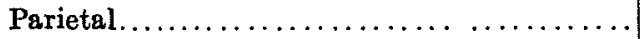 & 2.5 & 0 \\
\hline 9 & Occipital control. $\ldots \ldots \ldots \ldots \ldots \ldots \ldots \ldots \ldots$ & 2.5 & 0 \\
\hline 10 & Occipital,$\ldots \ldots \ldots \ldots \ldots \ldots \ldots \ldots \ldots$ & 2.5 & 50 \\
\hline 11 & Occipital............. & 2.5 & 65 \\
\hline 12 & Occipital $\ldots \ldots \ldots \ldots \ldots \ldots \ldots \ldots \ldots \ldots \ldots \ldots$ & 0.5 & 55 \\
\hline
\end{tabular}

This interpretation, derived largely from data on the dog and man, does not hold good for the rat. In it, at least in visual habit, long transcortical connections are not formed. The same area which functions as a sensory projection area seems to contain also corresponding motor fibers. A discussion of the bearing of this result upon the condition in higher animals will be left until one additional line of evidence upon the vicarious functioning of the cerebrum has been presented (section VI).

Is the loss of the habit an indication of a general "psychic blindness" or is it due only to the interruption of specific reflex arcs involved in the habit? As far as could be determined the 
animals could see perfectly well after the occipital destruction. Vision in the rat is difficult to detect without prolonged training, but some indication of vision is given by the following observations. The animals would jump up and grasp the edges of the training box accurately although the depth of the box was so great that they could not reach the top of it with their vibrissae, even when they stood on tip toe. They would also leap across a space too broad to be spanned by their vibrissae but showed greater hesitation in this than do normal animals. Finally they relearned the problem in no greater time than the average of normal animals, which could scarcely have occurred had they been handicapped by cortical blindness. The operation which destroyed the visual habit did not destroy the ability to see.

The destruction of the occipital pole did not result in a loss of all habits, but only in the loss of the visual one. The accurate running of the discrimination box requires not only the formation of the sensory habit but also a great many adjustments to the box. The animal learns to go directly through the alleys to the food, to turn back and pass through the discrimination compartment and second alley without a pause in case the wrong alley was chosen first, to claw at the door of the starting compartment in case the experimenter is slow in releasing him, and to grab a double handfull of food as the experimenter transfers him to the starting compartment. All these activities appeared in the rats with occipital lesions. The tactile and kinaesthetic motor habits were retained, only the visual habit was lost. Von Monakow ('14) has criticized Franz's experiments on the ground that they merely produced a 'protracted clouding of the sensorium' similar to that following skull-fracture in man and that the loss of habitual reactions after injury to the frontal lobes was merely a diaschesis effect (shockartige Störung). The complete elimination of one habit with the perfect retention of other probably no less complicated ones after occipital lesions speaks very strongly against Von Monakow's view and in favor of the one advanced above, that the loss is due to the interruption of specific reflex arcs. 
The exact delimitation of the visual area has not been made possible by these experiments, but the gross area determined seems to correspond to the histological findings. The majority of writers have localized the visual cortex of rodents on the posteromedial aspect of the cortex, behind the caudal fibers of the corpus callosum and in contact with the cerebellum (Isenschmid, '11). This region remained uninjured in all but one of my cases. It probably is not the part functional in the visual habit. Brodmann ('09), on the other hand, locates the area striata on the dorsal convexity of the occipital pole in the rabbit and Isenschmid

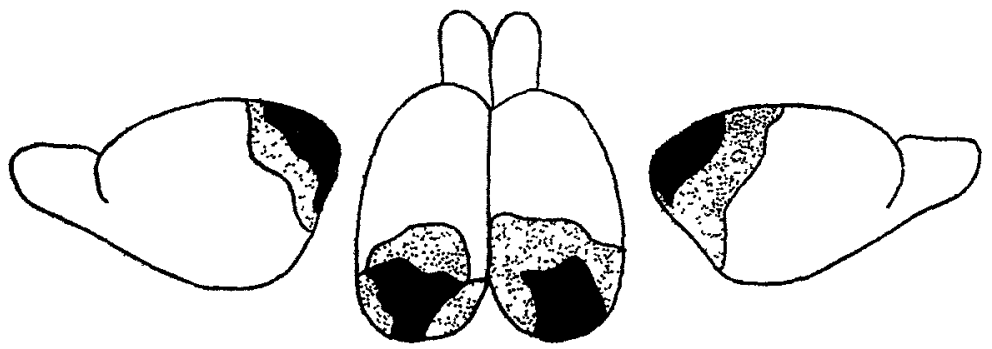

Fig. 12. Tae Total Extent of the Lesions in Animals Werch Lost the Habit of Visual Discrimination after Operation

The stippling shows the total area, the solid black the area common to all.

('11) is inclined to favor this view in his studies on the cytoarchitecture of the mouse's brain. Figure 12 shows the combined extent of the lesions in the three occipital cases. Only a small area on the dorsal convexity was destroyed in all three animals. This covers approximately the region described by Brodmann for rodents as the area striata. It is by no means certain, of course, that the region destroyed was the region functional in the habit, but the mass of evidence on cerebral function accumulated from the rat gives little indication of shock effects and the most probable interpretation of the data is that the loss of habit resulted from the destruction of Brodmann's area striata. 
V. THE STIMULABLE CORTEX AND THE CORPUS STRIATUM IN RELATION TO DISTURBANCES OF MOTOR COÖRDINATION

The investigations of the functional anatomy of the rat's brain thus far reported have all pointed to camplete interchangeability of function among the different parts of the cortex, and a complete and rapid recovery from the effects of cerebral operation. Butamong the 60 odd rats which have been subjected to operation and subsequent tests by Dr. Franz and the writer, there have appeared 9 with a persistent hemiparesis. Ordinarily, paralytic symptoms clear up very quickly, if they appear at all, in lower animals after cerebral destruction. In these animals, however, the paretic condition, affecting the fore and hind limbs of one side with sometimes the face, seemed to be almost permanent. Some of the paretic animals were kept under observation for four months and during this time made no perceptible spontaneous improvement in motor coördination. This persistent paresis is so strongly in contrast with the evanescent loss of other functions after cerebral injury as to arouse a special interest in its cause. Franz and the writer suggested a possible relation of the paresis to lesions of the corpus striatum but the material then available was not varied enough to settle the point. The present experiments have produced six additional cases and these give fairly conclusive evidence on the cause of the paresis.

The hemiparesis is easily recognizable by inspection as a stiffness, clumsiness, or weakness of the legs of one side. It usually leads to marked disturbance of gait, such as rotation to the right or left, but the direction of rotation has no constant relation to the position of the paralysis. A somewhat more certain analysis of the character of the motor disturbance was obtained by forcing the animals to climb down a vertical stretch of wire netting. Normal animals support their weight equally well with the feet of either side. Paretic animals can grasp firmly only with the feet of the sound side and fall if forced to turn so that the weight must be supported by the paretic legs. This test was applied only to animals in the later experiments and the data in these are therefore the more reliable. 


\section{The electro-stimulable cortex of the rat}

The portion of the rat's cortex from which movements maybe elicited by electrical stimulation have been described only by Ferrier ('76) and only in the barest outline. A more exact determination of its extent is necessary for this comparison. I have mapped the excitable cortex in about 25 animals. There is a great deal of variation an account of which must be postponed until a comparison of anesthetics is possible. Figure 13 is a composite picture of the excitable areas of these animals.
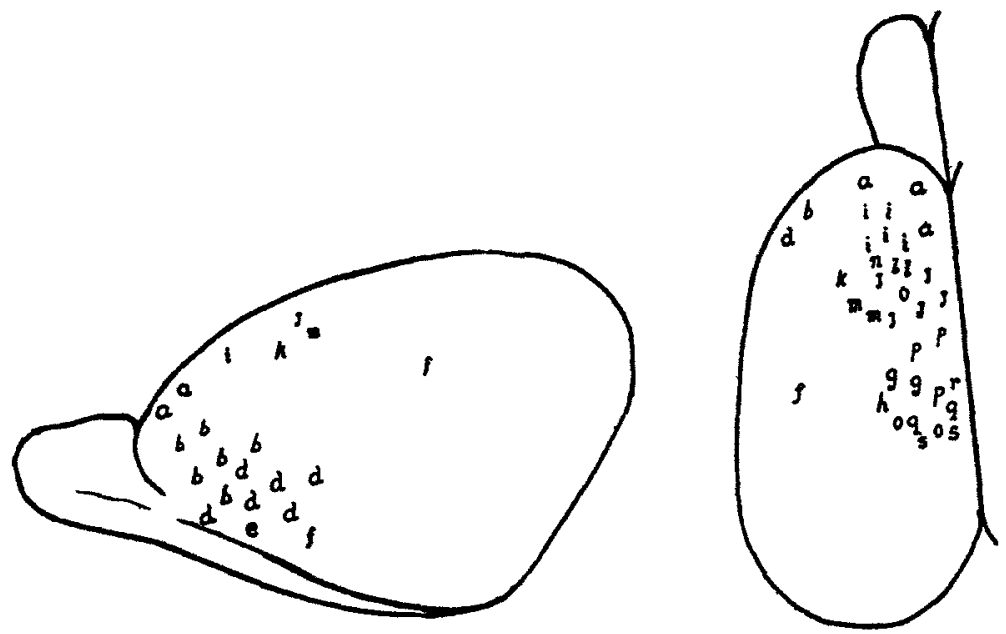

Fig. 13. Diagram of the Excitable Contex of the Rat

For the significance of the letters see text.

a. Head turned to opposite side

b. Nose retracted

c. Vibrissae moved

d. Chewing movements

e. Tongue protruded

$f$. Eye closed.

o. Ear laid back

$h$. Ear pricked up

$i$. Shoulder drawn forward

$j$. Fore-arm retracted k. Elbow flexed

l. Elbow extended

$m$. Wrist flexed

n. Fore-arm rotated

o. Back flexed to opposite side

p. Hind leg drawn forward

q. Homolateral leg flexed, ipselateral extended

$r$. Ankle extended

s. Tail drawn to opposite side.

All the movements elicited from all animals are shown, so that the diagram includes many more movements than can be ob- 
tained from any one animal. These movements, with their designation in the figure are listed above. Unless otherwise indicated the movement is on the contralateral side.

The stimulable area embraces all of the frontal pole in front of the forceps of the callosum and the dorso-medial portion as far back as the anterior margin of the hippocampal lobes. The responses elicited correspond roughly to the antero-posterior distribution of the muscles involved, the head having the most anterior representation. The responses are obtainable only under light anesthesia and are less well coördinated than in higher forms.

The relation of the stimulable cortex to paresis

In primates destruction of the stimulable cortex produces nearly complete paralysis, in the dog the paralysis persists for only a few days, in the rat destruction of this area produces no discoverable disturbance. The data included in this and the earlier studies contain a large number of cases of bilateral destruction of the motor cortex. Animals 4, 5, and 8, section III, of this paper all show extensive destruction of the stimulable areas of both hemispheres. Numbers $1,3,4,20$, and 28 of the series of Lashley and Franz ('17) show similar superficial bilateral lesions. None of these animals showed any persistent motor disturbance, although in many the destruction of the stimulable areas, either of one or both hemispheres, was practically complete. The paresis described does not result from destruction of the motor cortex.

The character of the lesions in paretic animals

The animals showing paresis and the character of the lesion in each are shown in table 9. Animals from the earlier series of Lashley and Franz are included with those of the present series. Since the experiment numbers of the two series are the same the animals of the former series are indicated by an asterisk. For detailed descriptions of the behavior and extent of the lesions in those animals the reader is referred to the original paper. 
The lesions of the animals of the present series are described in section III.

Of the cases included in the table one (number $14^{*}$ ) must be excluded because the brain was not sectioned, leaving eight significant cases. Two lesions are common to seven of these eight. They are destruction of the motor cortex and destruction of one corpus striatum. Number 14 alone shows no injury to the corpus

TABLE 9

The character of lesions in animals showing paretic symptoms

\begin{tabular}{|c|c|c|c|c|}
\hline$\underset{B E R}{\text { NOY- }}$ & PAREBIS & $\begin{array}{c}\text { DESTRUCTION OF MOTOR } \\
\text { AREA }\end{array}$ & $\underset{\text { BTRIATA }}{\text { DESTRECTION OF CORPORA }}$ & OTHER LEALONB \\
\hline $14^{*}$ & Left & Brain lost & & \\
\hline $38 *$ & Left & Complete & Right degenerated & Right fornix \\
\hline $39 *$ & Right & Complete & $\begin{array}{l}\text { Left degenerated; } \\
\text { Right injured(?) }\end{array}$ & Extensive \\
\hline 3 & Right & Unilateral & Left degenerated & $\begin{array}{l}\text { Left hemisphere } \\
\text { complete }\end{array}$ \\
\hline 4 & Left & $\begin{array}{l}\text { Unilateral; nearly } \\
\text { all }\end{array}$ & $\begin{array}{l}\text { Right posterior } \\
\text { part destroyed }\end{array}$ & Extensive \\
\hline 5 & Right & $\begin{array}{l}\text { Unilateral; nearly } \\
\text { all }\end{array}$ & $\begin{array}{l}\text { Left severed from } \\
\text { thalamus }\end{array}$ & Extensive \\
\hline 6 & $\begin{array}{l}\text { Right, } \\
\text { cleared } \\
\text { up }\end{array}$ & $\begin{array}{l}\text { Anterior part in- } \\
\text { tact }\end{array}$ & Left destroyed & Fornix \\
\hline 14 & Right & $\begin{array}{l}\text { Fore arm and leg } \\
\text { regions }\end{array}$ & Uninjured & None \\
\hline 19 & Right & Bilateral & Left degenerated & Slight \\
\hline
\end{tabular}

1 In the earlier description of this animal it was stated that the lesion passed through the right corpus striatum. In reëxamining the sections I find that the cut passed along the external capsule laterad to the C. S., and produced at most a very slight injury to it.

striatum and his paresis is questionable (p. 120). These are the only lesions common to all the paretic animals. Injury to the motor cortex alone has been shown to be incapable of producing paresis. There remains only the injury to the corpus striatum as a possible explanation of the motor disturbance. A further fact points to the corpus striatum as the source of paresis. In every case the paresis was on the side opposite the injured nucleus, irrespective of whether the lesion to the stimulable cor- 
tex was bilateral, as in numbers $38^{*}, 39^{*}, 14$, and 19 , or unilateral, as in the others.

But the immediate reference of the paresis to the corpus striatum was prevented by the fact that many of the animals which gave no indication of motor disturbance showed more or less extensive injuries to the corpora striata. This made necessary the reëxamination of the entire mass of material to determine the exact character of the lesions to the corpora striata in each case. The results of this are summarized in table 10. The lesions were worked up without reference to the behavior of the animals and classified as bilateral, unilateral, slight, and extensive. They were then coördinated with the behavior material. The result is a striking correspondence between extensive lesion to one corpus striatum and the appearance of the paresis. The table shows that no animal with bilateral injuries developed paresis: that no animal with slight injury to one corpus striatum developed paresis: that all but one animal (number $36^{*}$ ) with extensive dèstruction of one striate body showed pronounced hemiparesis. Horizontal sections from the brains of typical cases in each of these three groups are shown in plate IV, in which the figures bear the experiment numbers of the series of Lashley and Franz. Similar sections of all of the animals of the present series are given in plates I and II. From these a good idea of the actual extent of the injuries can be obtained.

Of the animals with extensive lesions to one striate nucleus only number $36^{*}$ failed to show pronounced paresis. A review of the original description of this animal revealed the fact that the animal had an initial preference for the right turn in the simple maze. A similar tendency to turn to one side occurs in all paretic animals and is much less frequent in normal animals. Further the direction of turning is that which most frequently results from right paresis (lesion in left hemisphere) so that it appears that this animal had a slight paresis which had remained undetected. If this interpretation is correct, it seems that every animal of the series which had an extensive destruction of one corpus striatum developed hemiparesis, and that this lesion is the only one of those recorded which does produce motor disturbance. 
One apparent exception to this rule still remains. It is number 14 (table 9 ) reported as having paresis. Reëxamination of the original data on this animal shows that the diagnosis of

TABIE 10

Summary of the condition of the corpora striata in all animals showing injuries to these structures, with the state of motor coordination. Sections of brains from the earlier series (*) are figured $(f)$ in plate IV; and from the present series in plates $I$ and $I I$

\begin{tabular}{|c|c|c|}
\hline NOMBER & Lesions то c. & $\begin{array}{l}\text { Motos } \\
\text { CONDITIOX }\end{array}$ \\
\hline \multicolumn{3}{|c|}{ Both corpora striata injured } \\
\hline $10 * \mathrm{f}$ & Both cut, not degenerated. & Normal \\
\hline $11 * \mathrm{f}$ & Both in jured and compressed by enlarged ventricals. & Normal \\
\hline $25 * \mathrm{f}$ & Both extensively injured $\ldots \ldots \ldots \ldots \ldots \ldots \ldots \ldots$ & Normal \\
\hline $26 * \mathrm{f}$ & Both transected in anterior region. . . . . . . . . . & Normal \\
\hline $27 *_{\mathrm{f}}$ & Both extensively injured. $\ldots \ldots \ldots \ldots \ldots \ldots \ldots \ldots$ & Spastic \\
\hline $29 *_{\mathrm{f}}$ & Both cut transversely $\ldots \ldots \ldots \ldots \ldots \ldots \ldots \ldots$ & Normal \\
\hline $30^{*}$ & Both cut transversely in anterior region.......... & Normal \\
\hline $32^{*}$ & Both injured extensively. ............... & Spastic \\
\hline $34^{*}$ & Both much shrunken (?)................. & Spastic \\
\hline \multicolumn{3}{|c|}{ One corpus striatum slightly injured } \\
\hline $22 *_{\mathrm{f}}$ & Left transected. & Normal \\
\hline $23 * \mathrm{f}$ & Left transected in anterior region. & Normal \\
\hline $33^{*}$ & Left, anterior third & Normal \\
\hline $37 * \mathrm{f}$ & Right very slightly injured... $\ldots \ldots \ldots \ldots \ldots \ldots \ldots$ & Normal \\
\hline \multicolumn{3}{|c|}{ One corpus striatum injured extensively } \\
\hline $36 * \mathrm{f}$ & Left destroyed & Paresis (?) \\
\hline $38 *_{\mathrm{f}}$ & Right degenerated. . & Paresis \\
\hline $39 * \mathrm{f}$ & Left destroyed..... & Paresis \\
\hline $3 \mathrm{f}$ & Left destroyed . & Paresis \\
\hline $4 f$ & Right severed from thalamus. & Paresis \\
\hline $5 f$ & Left severed from thalamus ....... & Paresis \\
\hline $6 f$ & Left destroyed.. & Paresis \\
\hline $19 f$ & Left destroyed... & Paresis \\
\hline
\end{tabular}

f, Figured; * first series.

paresis was made solely upon the fact that he earried his head twisted to one side. Fe supported his weight with the feet of either side. The twisted position of the head frequently devel- 
ops spontaneously and is probably due to cerebellar or semicircular canal trouble. It is possible that the condition in this case was of a similar sort and not due at all to the cerebral lesion.

In all the certain paretic cases described there was extensive lesion to the stimulable cortex as well as to the corpus striatum. Lesions to the stimulable cortex alone do not produce motor disturbance. Does lesion in the corpus striatum produce a paretic condition when the stimulable cortex is intact or do these two structures have an interchangeable function as Luciani ('15) suggests? In one case only, number 6 (plate I, figure 6), was any large portion of the stimulable cortex intact. The descriptions of this animal made subsequent to operation record a slight right paresis. This was no longer detectable, however, when training was begun, 30 days after operation. One case can not prove the point, but it suggests that the motor cortex may be able to compensate completely for the loss of the corpus striatum.

Bilateral injuries to the corpora striata are not followed by paresis. The spasticity noted in some of the cases (table 10) may perhaps be ascribed to the bilateral lesion since it appeared in animals having very extensive lesions, but none of these animals was kept long enough to assure that the spasticity was not the result of the general cerebral condition following operation. Moreover, a similar spasticity appeared in animals without lesions in the corpora striata, so that the function of these nuclei in producing it is questionable. Except for the few cases of spasticity the animals with bilateral injuries to the striate nuclei showed no motor disturbances. They were able to climb actively and showed no such weakness as appeared in hemiparesis. In animals number $10^{*}, 11^{*}, 27^{*}$, and $29^{*}$ the injuries to both striate nuclei were very extensive but there is no case in the series in which destruction of both nuclei was as great as that of one in the hemiparetic animals. It may be that the lack of motor disturbance in these animals is due only to the incomplete destruction of the nuclei, but in number $29^{*}$ (plate IV, figure $29^{*}$ ) there is indication of a complete section of the anterior two-thirds of the right nucleus from the thalamus and in numbers $10^{*}, 11^{*}, 25^{*}$, and $27^{*}$ also the lesions to one or both nuclei were very extensive. 
These cases suggest that there is an actual difference in the effects of unilateral and bilateral destruction; that destruction of the corpus striatum does not actually eliminate the coördinating mechanism, but merely destroys the balance of some regulatory mechanism which is useful when functioning normally but which may be dispensed with altogether provided that the loss is bilateral. Such a situation would be analogous to that presented by the semicircular canals, but more experimental data must be accumulated before the point can be established.

\section{The function of the motor area in learning}

These observations on paresis indicate that the stimulable cortex and some part or all of the corpus striatum have a similar motor function. Is it possible that neurones in either one of these structures may function as the final common path of a learned reaction in the absence of the other? If this were true it would explain the seeming restriction of visual habits to the occipital pole (section V) and the failure of complete destruction of the excitable cortex to abolish simple kinaesthetic-motor habits. The records include two cases which speak strongly against this, however. They are animals number $10^{*}$ and $11^{*}$ (plate IV, figures 10 and 11). Both of these animals showed complete destruction of the excitable cortex as a result of the two successive operations to which they were subjected and also very extensive injuries to the corpora striata. Nevertheless, both showed practically perfect retention of the simple maze. It is possible that the portions of the corpora striata remaining were sufficient to mediate the habit, but it seems unlikely that such extensive injuries to a functional area should not have produced some deterioration. Further, a number of cases (table 9) appear in which extensive injury to both corpora striata and the excitable cortex was not followed by any marked loss in ability to learn. Such results suggest that the motor areas may not be important for learning as such; that the function of the motor cortex may be maintenance of normal muscle tone and that habitual reactions may be superimposed upon this by impulses 
descending directly from other cortical regions. The problem is an interesting one and can be readily tested by careful operations.

\section{THE SIGNIFICANCE OF THE GENERAL RESULTS FOR THE} CEREBRAL MECHANISM OF LEARNING

The experiments recorded in this paper give no indication of the character of the reintegration of conduction paths which occurs in learning. That problem must wait for a physiological analysis of the factors which determine the direction of conduction in the nervous system and for much more detailed studies of the behavior of small groups of neurones in learning. But the experiments do give someinsight into the function of the anatomical divisions of the cerebrum in the acquirement and retention of habits and the course of the conditioned-reflex arcs through which learned reactions are mediated.

The point most clearly demonstrated is the complete vicarious functioning of all parts of the cerebrum in learning. Not only. are areas to which associative function might be ascribed unnecessary for the acquirement of habits but even projection areas, which have been considered as hereditarily organized relay stations for impulses to or from the cortex, may be dispensed, with without any discoverable loss in ability to learn a difficult reaction which is normally mediated by those areas. This capacity for vicarious functioning seems to hold true both for the cortex and for the underlying structures making up the archipallium. Such a fact can only be explained by the assumption of a fan-like distribution of fibers from the lower centers to all parts of the cerebrum, permitting incoming impulses to reach any part of the cortex, which happens to be intact, with equal ease.

Yet if this is the case, it is not clear why any particular part of the cortex should function to the exclusion of other parts in the formation of a habit under normal conditions, unless we can further assume a somewhat greater concentration of fibers from given lower centers in given cerebral areas. Probably this represents the true state of affairs, for it is evident from the fact that 
destruction of the frontal or occipital regions abolishes corresponding habits that under normal conditions the various parts of the cerebrum have specialized functions. Nevertheless this. specialization is only relative and is of such little practical consequence that learning may go on with equal speed in the presence or absence of the specialized areas.

The results further form a strong argument against the existence of any cerebral areas which have a directive influence over learning, whether it be by "attention," mediated through the frontal lobes or by the "conscious action" of the brain as a whole. On the contrary, they suggest that the only essential condition for learning is the simultaneous activity of two reaction systems which are in anatomical connection by association fibers.

By far the most suggestive of the results brought out by the experiments are those dealing with the function of the occipital pole and the corpus striatum. It is clear that the habit involving discrimination of brightness has no other cortical representation than the occipital region. The conditioned visual reflexes do not pass across the cortex to association or motor areas. The corpora striata seem to have an alternative function with the stimulable cortex for the control of motor coördination. Two possible hypotheses concerning the path of conditioned-visualreflex arcs are thus admitted. Either the impulses pass to the visual projection area in the occipital pole and thence to the corpus striatum, or they pass to the visual area and directly back to lower centers without traversing any long association fibers or reaching a cerebral motor area. Some evidence was found that the corpora striata are not necessary for the acquirement of motor habits and that the habit of the simple maze may be retained after the destruction of both the stimulable cortex and the corpora striata (section VI). The data on this point are not conclusive, but seem sufficient to raise the question of whether or not the neurones of the motor areas of the cerebrum really serve as the final common path of learned reactions. The possibility does not seem excluded by any evidence that I know of that the loss of motor control in paralysis is due, not to the interruption of conditioned-reflex paths, but to some disturbance in tonic 
innervation. The loss of voluntary movement in hemiplegia, pure motor aphasia, etc., might thus be due solely to the disturbance of some fundamental coördinating mechanisms, upon which the habitual reactions are superimposed, rather than to interruption of the habit-mechanisms themselves.

Existing evidence of the motor function of the corpora striata has been rather uncertain. Luciani ('15) and others have obtained movements from stimulation of the caudate nucleus but Von Bechterew ('09) claims that this was due to spread of current and that no movements can be elicited if degeneration of the internal capsule is first induced. The data given in section VI seem to show the motor function of the striate nucleus conclusively.

With what justice may results on cerebral function found for the rat be extended to higher forms? The rat has a very primitive cerebral organization but I doubt that this justifies the assumption that there is any fundamental difference in cerebral mechanism between the rat and even man. "The chief arguments which have been advanced for the greater specialization of cerebral function in higher forms have been the lack of paralysis from destruction of the motor cortex in animals below the primates, rapid recovery from sensory defects after destruction of afferent projection areas in lower forms, and the increasing number and complexity of histologically distinct cortical areas with advancement in the evolutionary scale. The significance of the last point is questionable. The rat has many areas distinct in cytoarchitecture but these seem to have no absolute functional significance. The data on the striate nuclei suggest that the motor area is quite distinct in the rat, but with a predominance of function in the subcortical nuclei which is assumed by the motor cortex in higher forms. As for the greater loss of sensory and intellectual capacities and the slower recovery which appears after cerebral injuries in higher forms, they are restricted largely to man. The differences between the rat and the apes are scarcely greater than those between the apes and man. Both the sensory and intellectual capacities of the adult man are the result of years of training which have led to the establishment of countless 
habits having a definite structural basis. Cerebral injury may destroy a very great number of these, instead of the few which such an animal as the rat has formed, and the apparent loss of function will therefore be greater. Further, the rate of learning in the human adult depends largely upon the number and complexity of the habits already organized. When the latter are abolished the entire system must be built up slowly de novo before anything like an approach to adult performance is attained. The recent studies of reëducation in hemiplegia, aphasia, and apraxia show that the loss from cerebral lesions is never necessarily permanent in man and that an unlimited though slowly acquired vicarious functioning is possible. The difference seems to be one of degree rather than of kind. The rat loses less than higher forms after cerebral injury because he has less to lose and he seems to recover more rapidly chiefly because a little improvement brings him relatively nearer the standard of comparison (normality) than does the same amount of improvement in man.

\section{Summary}

1. Destruction of the frontal pole, including the motor area, is probably followed by an increase in general activity. Injuries to other parts of the cerebrum have no dynamogenic effect.

2. Learning at normal rate of either kinaesthetic- or visuomotor habits is possible after the destruction of any given part of the cerebral cortex of the rat.

3. Destruction of cerebral nuclei also has no effect upon the rate of learning.

4. Within limits from 100 to 50 per cent of the cortex there is no relation between the amount of cerebral material functional and the rate of formation of complex habits.

5. In normal animals the habit of brightness discrimination is mediated by the occipital pole of the cerebrum (area striata) and by no other part of the cerebral cortex.

6. Extensive lesions to one corpus striatum are accompanied by paralytic symptoms and it is probable that the stimulable cortex and the corpora striata have alternative motor functions. 


\section{REFERENCES}

Barenne, J. G. D. DE: Sensory localization in the cerebral cortex. Q. J. Exp. Physiol., 1916, ix, 355-390.

Bechterew, W. v.: Die Funktionen der Nervencentra. Jena, 1909.

Bolton, J. S.: Amentia and dementia: A clinico-pathological study. Part III. Dementia. Jour. Mental Sci., 1905, lii, 221-277 et seq.

Brodanan, K.: Vergleichende Lokalisationslehre der Grosshirnrinde. Leipzig, 1909.

BunnetT, T. C.: Some observations on decerebrate frogs with especial reference to the formation of associations. Amer. J. Physiol., 1912, xxx, 80-87.

Dodson, J. D.: Relative values of reward and punishment in habit formation. Psychobiology, 1917, i, 231-276.

Dunzap, K.: Internal Secretion in Learning. Psychobiology, 1917, i, 61-64.

Ferrier, D.: The functions of the brain. New York, 1876.

Franz, S. I.: On the functions of the cerebrum: I. The frontal lobes in relation to the production and retention of simple sensory-motor habits. Amer. J. Physiol., 1902, viii, 1-22.

Franz, S. I.: On the functions of the cerebrum: The frontal lobes. Archives of Psychol., 1907, no. 2, pp. 64 .

Franz, S. I., and Lashley, K. S.: The retention of habits by the rat after destruction of the frontal portion of the cerebrum. Psychobiology, 1917, i, 3-18.

Goutz, F× Der Hund ohne Grosshirn. Arch, f. d. ges. Physiol., 1892, li, 570-515.

Isenschard, R.: Zur Kenntnis der Grosshirnrinde der Maus. Abh. d. Königl. Preuss. Akad. d. Wiss., 1911, 1-76.

KAPPERS, Ariëns. Further contributions on neurobiotaxis No. IX. An attempt to compare the phenomena of neurobiotaxis with other phenomena of taxis and tropism. The dynamic polarization of the neuron. Jour. Comp. Neurol., 1917, xxvii, 261-298.

Kepner, W. A., and Taliaferro, W. H.: Reactions of Amoeba proteus to food. Biol. Bull., 1913, xxiv, 411-429.

LASHLEY, K. S. : Visual discrimination of size and form in the albino rat. Jour. Animal Behav., 1912, ii, 310-331.

LASHLEY, K. S.: The color vision of birds. I. The spectrum of the domestic fowl. Jour. Animal Behav., 1916, vi, 1-26.

LASHLEY, K. S.: The effects of strychnine and caffeine upon the rate of learning. Psychobiology, 1917, i, 141-170.

Lashlex, K. S., and Franz, S. I.: The effects of cerebral destruction upon habit formation and retention in the albino rat. Psychobiology, 1917, $i$, 71-140.

Leyton, A. S. F., AND Sherringron, C. S.: Observations on the exeitable cortex of the chimpanzee, orang-utan, and gorilla. Q. J. Exp. Physiol,, 1917, $\mathrm{xi}, 135-222$.

LOEB, J.: Comparative physiology of the brain and comparative psychology. New York, 1900.

LuCIaNi, L.: Human physiology, vol. iii. London, 1915.

Metalnikow, S.: Contributions a l'etude de la digestion intracellulaire chez les protozaires. Arch. d. zool. exp. et gen., 1912, ix, 373-499. 
Meyer, M.: The fundamental laws of human behavior. Boston, 1911.

Monakow, C. v.: Die Lokalisation im Grosshirn. Weisbaden, 1914.

MORGAN, L.: Instinct and intelligence. London, 1912.

Rothman, M.: Demonstration des Hundes ohne Grosshirn. (Ber. uber. d. V. Kongress f. exper. Psychol.) Leipzig, 1912, 256-260.

Sranp, R. G.: Diplodinium Ecaudatum; with an account of its neuromotor apparatus. U. of Calif. Pub. Zool., 1914, xiii, 43-122.

Slonaker, J, R.: Description of an apparatus for recording the activity of small mammals. Anat. Record, 1908, ii, 116-122.

Solmìr, P.: Le Problèm de la Mómoire. Paris, 1900.

TAYLOR, C. V.: The Neuromotor system of Euplotes. Proc. Soc. Exp. Biol., and Med., 1909, xvi, 101-103.

Warson, J. B.: Behavior. New York, 1914.

Yocom, H. B.: The neuromotor apparatus of Euplotes patella. U. of Calif. Pub. Zool. 1918, xviii, 337-396.

\section{PLATE I}

The extent of lesions in animals which lesrned the double-platform box after operation. The figures are arranged in groups of four, representing the dorsal and lateral aspects of the hemispheres and a horizontal section at the level of the ventricals. The degenerated areas are shown in black. Other areas certainly non-functional are dotted.

Fras. 1-6. Injury to one hemisphere only (group 2).

Fras. 7-9. Occipital cases (group 3). 

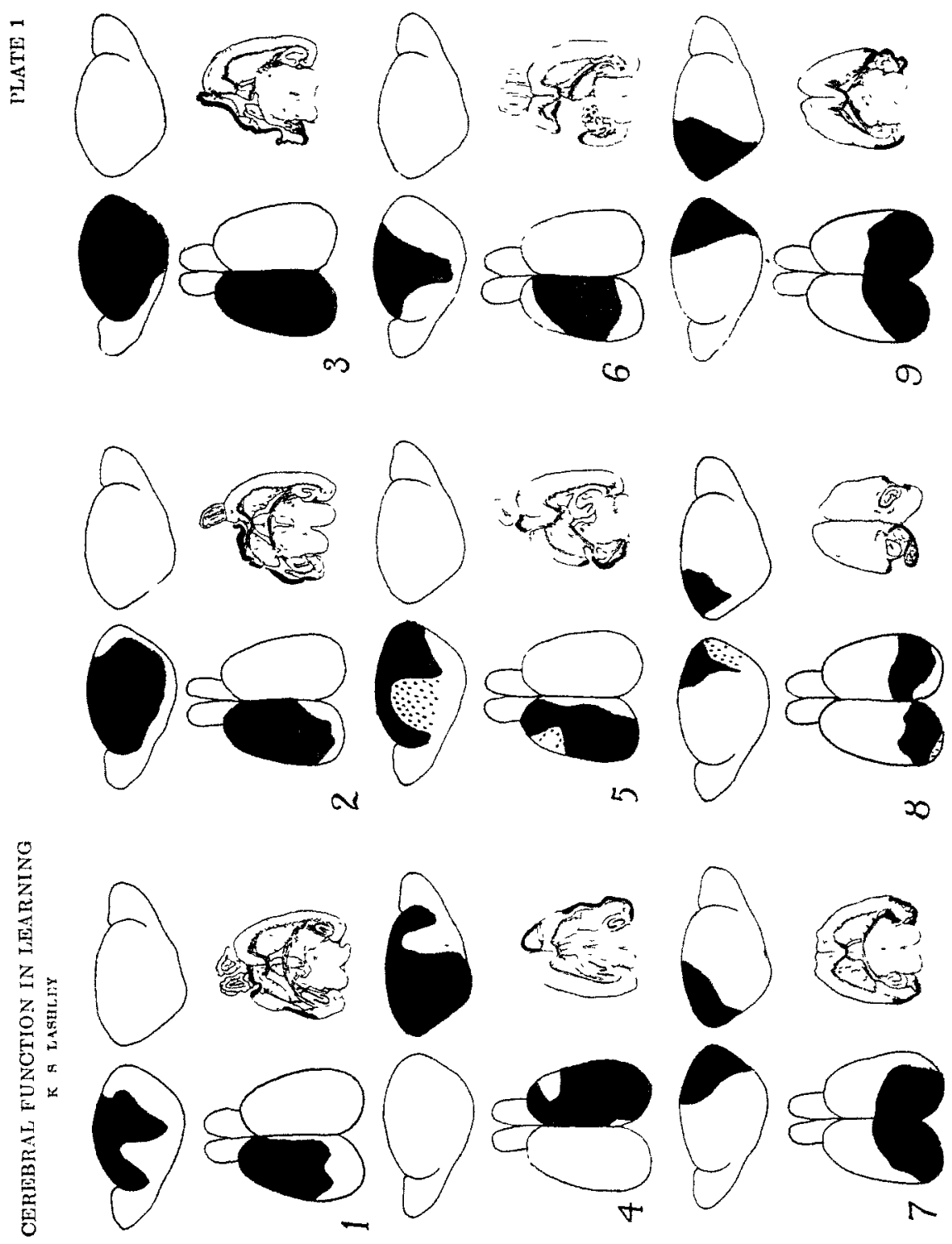

艺
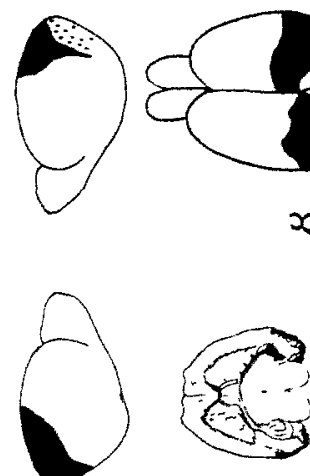


\section{PLATE II}

The extent of lesion m anmal whrch learned the double-platform box after operation, continued.

lig 10 ()eclpital case (group as

Flis. 11-15 Parretal (aser (group) 4 )

FIG. 16 (17). Fiontal cases, dentical (gioup 5).

FJG $18-19$ Fionto-parletal canes (gioup 6 ). 

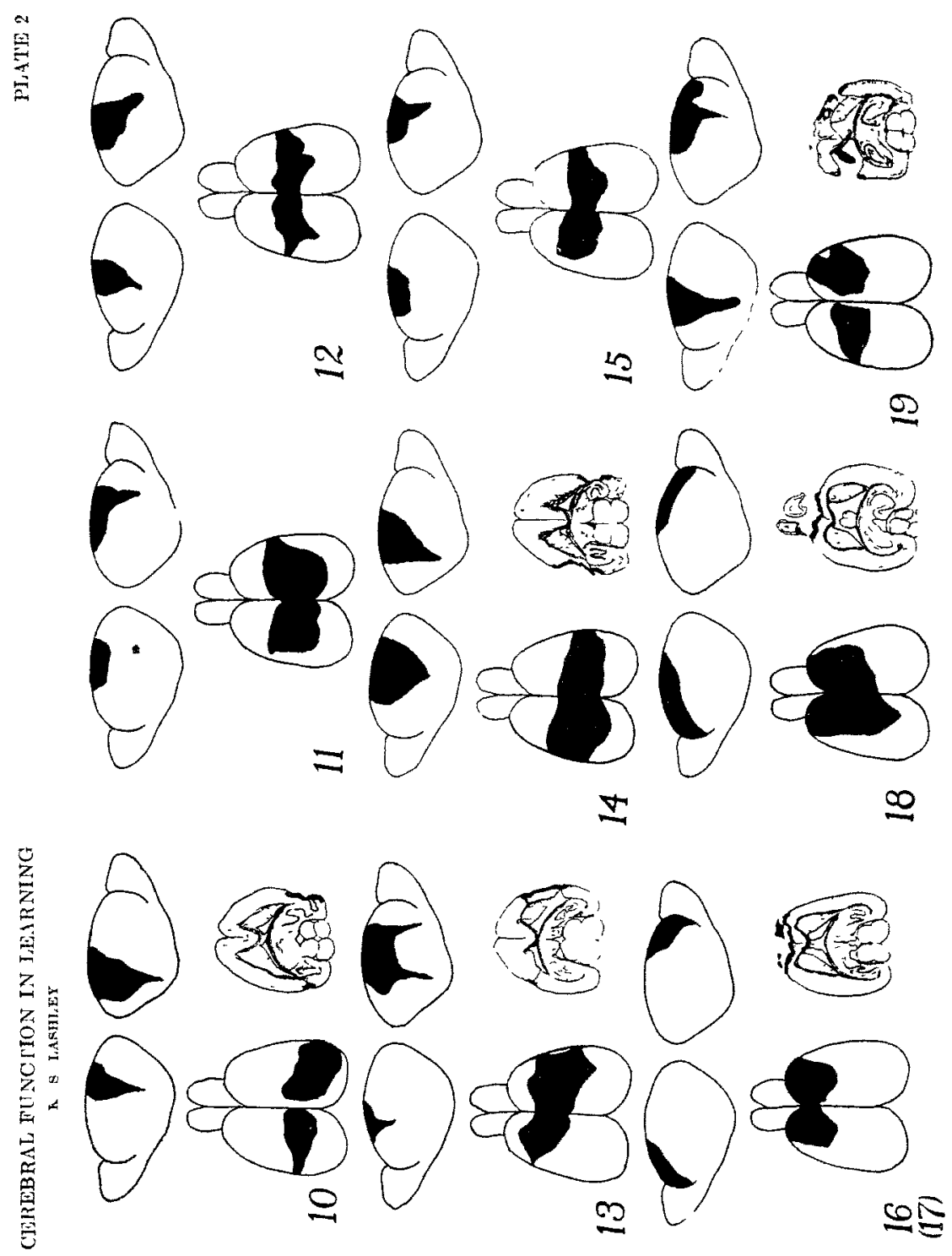


\section{PLATE III}

The extent of lentons an anmmal- tramed on visual dischmmation Arranged as plate I

Iises 14 Anmuls wheh formed the habit of brighness discrmmation after operation.

Fin 5-6. Anmals with desturetun of the frontal pole which retaned the vinual habit after operation.

Figm, T-8 Anmaks with destruetion of the parietal region which retaned the habit of visual deserimination after operation

Lise 9 Oecipital control

Figs 10-12. Animals which lont the habit of visual diserimination after orcipital lessons. 


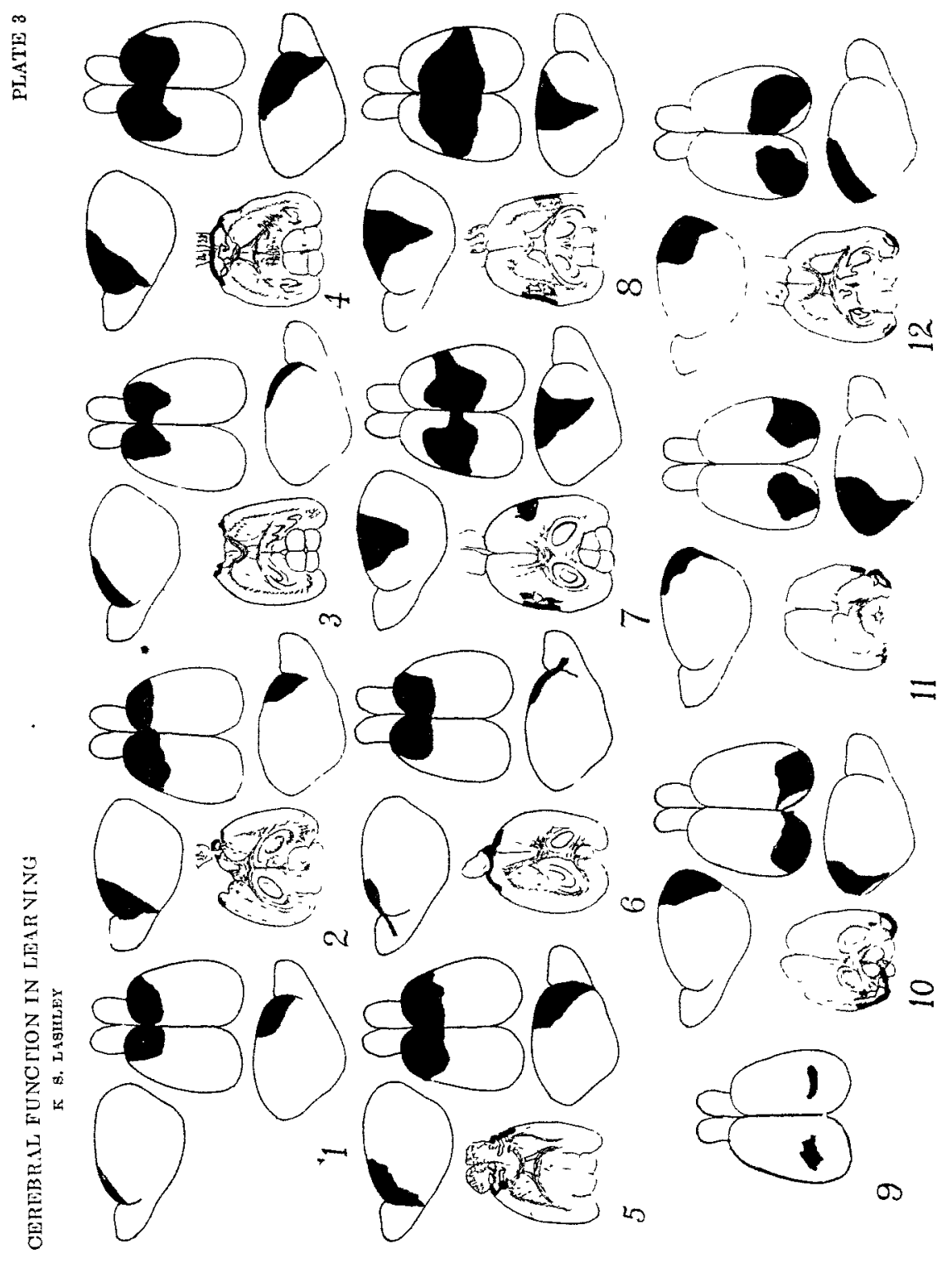




\section{PLATE IV}

The extent of in jury to the corpora strata and other unbertical stu uctures in typucal cases reported by Lashley and Franz ('17).

Fus. $10^{*}, 11^{*}, 25^{*}, 26^{*}, 27^{*}, 29^{*}$ Injures to both corpora struata without paretic symptoms.

Fres. $22^{\prime}, 23^{*}, 37^{\wedge}$ silight mulues to one corpus stratum without paretic symptoms

FIG $36^{*}, 38^{*}, 39^{k}$. Extensive injuries to one corpus striatum with paresis of legs of opposite side. 

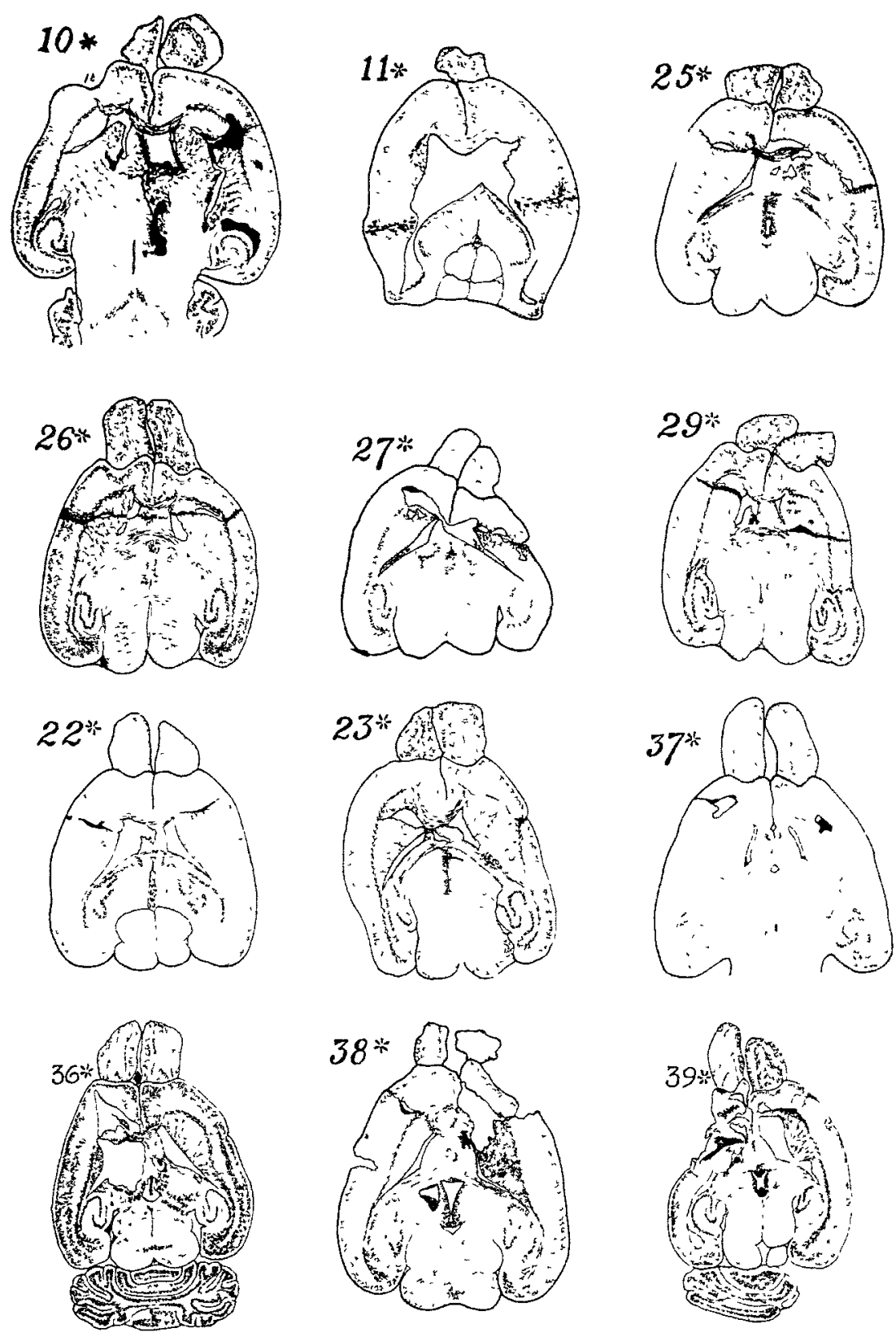